\title{
Lignin Recovery from Spent Alkaline Pulping Liquors Using Acidification, Membrane Separation, and Related Processing Steps: A Review
}

\author{
Martin A. Hubbe, ${ }^{*, a}$ Raimo Alén, ${ }^{\mathrm{b}}$ Michael Paleologou, ${ }^{\mathrm{c}}$ Miyuru Kannangara, ${ }^{\mathrm{d}}$ and \\ Jonas Kihlman $^{\mathrm{e}}$
}

\begin{abstract}
The separation of lignin from the black liquor generated during alkaline pulping is reviewed in this article with an emphasis on chemistry. Based on published accounts, the precipitation of lignin from spent pulping liquor by addition of acids can be understood based on dissociation equilibria of weak acid groups, which affects the solubility behavior of lignin-related chemical species. Solubility issues also govern lignin separation technologies based on ultrafiltration membranes; reduction in membrane permeability is often affected by conditions leading to decreased solubility of lignin decomposition products and the presence of colloidal matter. Advances in understanding of such phenomena have potential to enable higher-value uses of black liquor components, including biorefinery options, alternative ways to recover the chemicals used to cook pulp, and debottlenecking of kraft recovery processes.
\end{abstract}

Keywords: Black liquor; Acid precipitation; Ultrafiltration; Colloidal stability; Solubility; Debottlenecking of pulp mills; Carbon dioxide; Sulfuric acid; Lignin isolation

Contact information: a: North Carolina State University, Department of Forest Biomaterials, Campus Box 8005, Raleigh, NC, 27695-8005, USA; b: University of Jyväskylä, Department of Chemistry, POB 35, Jyväskylä 40014, Finland; c: FPInnovations, 570 St Jean Blvd, Pointe Claire, PQ H9R 3J9, Canada; d: Natl Res Council Canada, Energy Min. \& Environm., 1200 Montreal Rd, Ottawa, ON K1A OR6, Canada; e: Karlstad University, Department of Engineering and Chemical Sciences, SE651 88 Karlstad, Sweden; *Corresponding author: hubbe@ncsu.edu

\section{Contents}

Introduction . . . . . . . . . . . . . . 2301

Black liquor properties ... . . . . 2303

Main components \& proportions. 2303

Lignin in black liquor . . . . . . . . 2304

Polysaccharides in black liquor . 2307

Monomers in black liquor . . . . . 2307

Viscosity issues . . . . . . . . . . . . 2307

Emulsified lignin . . . . . . . . . . 2308

Factors affecting lignin separation. 2309

Overview ... . . . . . . . . . 2309

$\mathrm{pH}$ and $\mathrm{p} K_{a}$ values . . . . . . . . . . . . . 2310

Acid type . . . . . . . . . . . . . 2311

Temperature . . . . . . . . . . . 2314

Black liquor solids . . . . . . . . . 2315

Coagulation by cationic agents. . 2315

Stirring . . . . . . . . . . . . . . 2318

Stabilizers . . . . . . . . . . . . . 2319

Polysaccharides . . . . . . . . . . 2319

Solubility issues . . . . . . . . . . 2319
Interventions . . . . . . . . . . . . . . . 2320

Operations . . . . . . . . . . 2321

Membrane technologies . . . . . 2322

Overview of membranes ... . 2322

Solubility \& membrane use. . . 2324

Type of primary membrane. . . 2324

Membrane material . . . . . . . 2326

Pre-membrane . . . . . . . . . 2326

Electrolysis ........... 2326

Membrane process operation. 2327

The value of separated lignin. . . 2327

Lignin's value by itself . . . . . . 2327

Further fractionation . . . . . . . 2329

Debottlenecking of pulp mills. 2329

LignoBoost . . . . . . . . . 2330

LignoForce . . . . . . . . . . 2331

SLRP . . . . . . . . . . . 2332

Alternatives to recovery boiler 2333

Final thoughts . . . . . . . 2334 


\section{INTRODUCTION}

When the word "recovery" is used in the context of the pulping industry, the main focus has been on restoring the starting composition of the mixture of sodium hydroxide and sodium sulfide, which are used in the kraft process to break down and dissolve the lignin component of the wood or other cellulosic source material (Rydholm 1965; Marton 1971; Grace et al. 1989; Biermann 1996; Fardim 2011). Such pulping liberates the cellulosic fibers, whereas most of the lignin and degradation products from much of the hemicelluloses originally present in the biomass are typically incinerated in a recovery furnace, which provides steam to power the whole operation and to dry the resulting paper (Grace 1992; Adams 1997; Vakkilainen 2007; Empie 2009; Alén 2011; Bajpai 2017). The present review article considers technologies aiming to achieve a further goal - recovery of the lignin present in spent liquor from kraft pulping, i.e. "black liquor". Emphasis is placed on chemical aspects when separation of lignin is induced by acidification, by the use of membranes, and by some other related technologies.

In general terms, lignin can be described as a three-dimensionally cross-linked polymer formed biologically from phenol-propane-type monomer units (Sjöström 1993). There can be a variety of motivations to recover lignin rather than allow all of it to be incinerated during a traditional chemical recovery process at a pulp mill. Chemical pulping accounts for about $70 \%$ of the total worldwide production of pulp, i.e. chemical, semichemical, chemimechanical, and mechanical pulps (FAOSTAT 2014). The kraft process, which uses $\mathrm{NaOH}$ and $\mathrm{Na}_{2} \mathrm{~S}$ to break down and solubilize lignin from the cellulosic source material, accounts for about $90 \%$ of the world's chemical pulp production. When excluding mechanical pulps, the kraft process may account for $90 \%$ of the pulp production (Sixta 2006; Alén 2011; Gellerstedt et al. 2013).

In existing pulp mills where recovery is the capacity-limiting factor, one of the strongest motivations for lignin recovery can be to "debottleneck" the process. Removal of lignin from the black liquor can allow greater pulp production at such a pulp mill in which the capacity of the recovery boiler system is limited by the calorific load or the solids load (Axelsson et al. 2006; Ohman et al. 2007b; Mesfun et al. 2014). Two systems of black liquor acidification, separation, washing, and recovery of much of the lignin have been implemented in pulp mills, and these are called LignoBoost (Wallmo et al. 2009a,b; Tomani 2010; Tomani et al. 2011; Gellerstedt et al. 2013; Zhu et al. 2014, 2016) and LignoForce (Kouisni et al. 2012, 2014, 2016). Another system that has been demonstrated at a pilot scale is the Sequential Liquid-lignin Recovery and Purification (SLRP) system (Lake and Blackburn 2011, 2016; Kihlman 2016).

Another key motivation for lignin recovery is to utilize it for such higher-value applications as carbon fiber, phenolic resins, and activated carbon (Coheen 1981; Pye 2006; Bozell et al. 2007; Kouisni et al. 2011; Gellerstedt et al. 2013; Alén 2015; Zhu and Theliander 2015; Yahya et al. 2015; Suhas et al. 2016; Teguia et al. 2017). However, probably due to the complex structure of lignin, progress in implementation of such valueadded options has been slow. Lignin also can be utilized as a portable fuel (Uloth and Wearing 1989b; Tomani 2010) or as feedstock for preparation of biodiesel, which in some cases may have higher value than combustion of the material as part of a chemical recovery process in a pulp mill. Finally, there may be opportunities to rethink the entire pulping process as a biorefinery in which multiple chemical compounds, including breakdown products of polysaccharides, are fractionated, making them available as replacements for 
petroleum-based chemicals (Alén et al. 1989; Moshkelani et al. 2013; Alén 2015; Kumar et al. 2016; Teguia et al. 2017).

Though the main focus of this article is on the lignin present in kraft black liquor, it is important to keep in mind that the properties of lignin can be diverse, depending on its source (e.g. hardwood vs. softwood) and isolation procedures (e.g. kraft, soda, sulfite, or organosolv pulping, or enzymatic hydrolysis). These differences have been addressed elsewhere (Sarkanen and Ludwig 1971; Lora 2008; Vishtal and Kraslawski 2011; CalvoFlores et al. 2015).

To provide a focus for this article, a hypothesis can be proposed that the separation of lignin from black liquor can be understood based on the principles of solubility (Marcus 1993; Norgren et al. 2002b; Hansen 2007) and of colloidal stability (Lindström 1979, 1980; Nyman et al. 1986; Norgren et al. 2002a; Hubbe and Rojas 2008; Fritz et al. 2017). When acidification methods are used to separate lignin, it has been shown that the variables $\mathrm{pH}$, temperature, salt concentrations, the presence of coagulating ions, and the lignin type can play governing roles with respect to lignin separation. Also, the results can be highly dependent on the details of black liquor composition and pretreatments such as oxidation. Alternatively, ultrafiltration membranes (Jönsson et al. 2008; Humpert et al. 2016; Kevlich et al. 2017) and electrochemical methods can be used to separate lignin from black liquor (Jin et al. 2013; Haddad et al. 2016, 2017a). This review will consider each of these approaches, in turn.

The present article draws upon progress already achieved in earlier reviews of aspects of the topic. Humpert et al. (2016) and Kevlich et al. (2017) reviewed membrane technologies for recovery of lignin from black liquor, with emphases on the purity of the isolated lignin and process economics. Aro and Fatehi (2017) reviewed the related topic of separation of tall oil (extractives) from black liquor. In the context of the present article, one needs to be concerned about any tendency of extractives to co-precipitate with lignin when black liquor is acidified. Such co-precipitation renders the lignin less pure, which may decrease its value for certain potential applications (Norgren and Edlund 2014). Background of colloidal stability and coagulation of lignocellulosic materials also has been reviewed (Hubbe and Rojas 2008). Zhao et al. (2016) reviewed potential product opportunities based on recovered lignin as a starting material.

Lignin isolation also has the potential to serve as an initial step in alternative technologies aimed at the recovery of inorganic components from black liquor, as described in a recent review paper (Hubbe et al. 2018). Such approaches may be worth considering in situations where conventional recovery boiler operations are judged to be problematic or too expensive in relation to the production goals. For instance, when pulping grasses, such as straw and bamboo, the black liquor from pulping can be difficult to process in a conventional recovery boiler due to deposition of silica (Gilarranz et al. 1998; Mandavgane and Subramanian 2006). In such cases there is a motivation to find other ways to process the material. Removal of lignin and extractives from black liquor also can open the possibility for eutectic freeze crystallization and related technologies, which have potential to supplement the capacity of a pulp mill recovery system (Hubbe et al. 2018).

To provide background for discussions of separation of lignin by acidification, membranes, and related technologies, the next section will review some essential features of typical black liquor specimens. 


\section{BLACK LIQUOR PROPERTIES RELATIVE TO LIGNIN PRECIPITATION}

\section{Main Components and Proportions}

Lignin is a major, but not the only non-water component of black liquor (Frederick 1997). According to Nagy et al. (2010), kraft pulping typically removes 85 to $93 \%$ of the lignin and 56 to $71 \%$ of the hemicelluloses present in wood, so that the breakdown products of these materials comprise the major non-water content of black liquor. Humpert et al. (2016) reported typical weak black liquor compositions of 12 to $18 \%$ solids content. Crude turpentine is recovered from the digester relief and evaporator condensates, and most of the tall oil soap is removed during the black liquor evaporation process by skimming (Alén 2011). After the recovery of the majority of extractives-based compounds, the remaining black liquor dry matter mainly contains 25 to $35 \%$ lignin, 30 to $35 \%$ aliphatic carboxylic acids, 5 to $10 \%$ other organics (i.e., extractives- and hemicelluloses-derived residues and methanol), and 30 to $40 \%$ inorganics (i.e., the residual cooking chemicals and sodium and sulfur bound to organics) (Frederick 1977; Niemelä and Alén 1999; Alén 2011, 2015, 2018; Humpert et al. 2016; Kevlich et al. 2017). The fraction of aliphatic carboxylic acids comprises "non-volatile" hydroxy carboxylic acids (with an $\mathrm{OH}$ group located in alpha position relative to the carboxylic acid group) (20 to $30 \%$ of the dry solids) and "volatile acids", such as formic acid (about 5\% of dry solids) and acetic acid (5 to $10 \%$ of the dry solids). The composition of black liquor is characteristically dependent on the wood species and delignification conditions. Typically, softwood black liquors contain more lignin and less aliphatic carboxylic acids (especially, acetic acid) and other organics (especially, xylan residues) than hardwood black liquors.

During alkaline kraft pulping, the presence of hydrogen sulfide ions greatly facilitates delignification because of their strong nucleophilicity in comparison with hydroxyl ions, which are the only pulping agent present in soda pulping (Sjöström 1993; Alén 2000b; Hon and Shiraishi 2001). However, in the course of both kraft and soda pulping, lignin undergoes more or less drastic degradation reactions resulting from the liberation of phenolic hydroxyl groups - they are dissociated to sodium phenolates - with the simultaneous increase in hydrophilicity of lignin fragments. Hence, soda lignins are chemically rather similar to those from kraft pulping. Soda pulping is mostly used for nonwood or annual plants providing sulfur-free lignin.

The partial degradation and dissolution of lignin during alkaline pulping can be attributed to cleavage of certain types of chemical bonds in the lignin matrix. Nowadays all the relevant reaction mechanisms are well understood (Gierer 1970, 1980, 1982, 1985; Sjöström 1993; Hon and Shiraishi 2001). Typically in kraft pulping a significant cleavage of $\alpha$ - and $\beta$-aryl ether linkages between phenylpropane units (in both non-etherified and etherified phenolic units) takes place. For example, in the case of $\beta$-aryl ether linkages in non-etherified phenolic structures, the first step of the degradation reaction results, via the cleavage of the $\alpha$-ether bond, in a quinone methide intermediate. In kraft pulping this intermediate readily reacts with hydrogen sulfide ions, leading to simultaneous cleavage of the $\beta$-ether bond. However, in the case of soda pulping, when only hydroxyl ions are present, this essential degradation reaction is not prominent, and instead mainly an undegradable styryl aryl ether structure is formed. In general, kraft and soda lignins have more hydroxyl groups and relatively more carbon-carbon bonds than native lignins.

The inorganic chemical content of black liquor depends on many factors, such as wood feedstock, alkali charge, sulfidity, and cooking conditions. About $60 \%$ of the sodium that is present in black liquor can be assigned to a balancing of charge of the organic acid 
species, which include carboxylate and phenolate salts. The average composition of the fraction of individual inorganic compounds (as \% of the total compounds) in typical black liquor is 35 to $40 \% \mathrm{Na}_{2} \mathrm{CO}_{3}, 5$ to $10 \% \mathrm{NaOH}, 15$ to $20 \% \mathrm{Na}_{2} \mathrm{~S}, 5$ to $10 \% \mathrm{Na}_{2} \mathrm{SO}_{3}, 15$ to $20 \% \mathrm{Na}_{2} \mathrm{~S}_{2} \mathrm{O}_{3}, 10$ to $15 \% \mathrm{Na}_{2} \mathrm{SO}_{4}$, and about $10 \%$ others (Clayton et al. 1989; Niemelä and Alén 1999). Besides these major components, a large number of other inorganic components (non-process elements) are present, some of them occurring in trace amounts, and their comprehensive analysis is complicated. Additionally, Kevlich et al. (2017) reported levels of 0.2 to $0.7 \%$ silica (in the case of wood) and 1 to $30 \%$ (in case of nonwood sources of cellulosic fibers). Aspects of the inorganic components of black liquor and their recovery are considered in more detail in a companion article (Hubbe et al. 2018).

\section{Lignin in Black Liquor}

Acidic groups

Native lignin is considerably changed during the course of kraft (or other alkaline) pulping. Kraft pulping is especially effective at cleaving phenolic $\beta$-aryl ether linkages within the lignin, thus liberating fragments of much reduced molecular mass (Gustafsson et al. 2008).

According to Sjöström (1989), the acidic groups associated with lignocellulosic materials can be arranged as shown in Table 1, where the prevalent species are shown with bold lettering. It should be noted that the R-COOH compounds would include the fatty acids and (in the case of softwood) resin acids that are part of the tall oil, but this component is ordinarily removed from black liquor in their soap form by skimming (Dong et al. 1996; McGinnis et al. 1998; Pirttinen et al. 2007; Aro and Fatehi 2017). Sjöström (1989) noted that extractives tend to be removed effectively from fibers during alkaline pulping; on the other hand, the lignin component tends to develop more acidic groups during pulping. As noted by Ragnar et al. (2000), though many of the phenolic groups in lignin have $\mathrm{p} K_{a}$ values as shown in Table 1, typical lignin contains structures having $\mathrm{p} K_{a}$ values in the range of about 7.4 to 11.3 , depending on molecular connections to electron-donor groups or electron-withdrawing groups. In general, oxygen-containing functions adjacent to the aromatic ring tend to yield lower values of $\mathrm{p} K_{a}$. Acidity increases as the oxidation state of a para-substituted function is changed from methyl to hydroxymethyl to carboxylic acid to aldehyde.

Table 1. Acid Dissociation Constants $\left(p K_{a}\right)$ in Lignocellulosic Materials

\begin{tabular}{|l|l|l|}
\hline Type of Group & Prevalence & $\mathrm{p} K_{\mathrm{a}}$ value \\
\hline R-CH(OR')COOH & major & $\mathbf{3}$ to $\mathbf{4}$ \\
\hline R-COOH & minor & 4 to 5 \\
\hline RCO-phenyl-OH & minor & 7 to 8 \\
\hline Phenyl-OH & major & $\mathbf{9 . 5}$ to 10.5 \\
\hline Hemiacetalic & major & 12 to 12.5 \\
\hline Alcoholic & major & 13.5 to 17 \\
\hline
\end{tabular}

Note: Data as reported by Sjöström (1989)

Molecular representations of the composition of native lignins generally show few, if any, carboxylic acid groups (Sjöström 1993; Frederick 1997), and certainly not enough of them to justify the emphasis depicted in Table 1. A reason to expect such groups to play an important role with respect to the solubility properties of kraft lignin is due to the

Hubbe et al. (2019). "Lignin recovery review," BioResources 14(1), 2300-2351. 
presence of lignin-polysaccharide complexes (Lawoko et al. 2005, 2006; Gellerstedt et al. 2013; Tarasov et al. 2018). Rather than being separate, the lignin and hemicellulose components of woody materials appear to be covalently bonded together, to some degree, in their native state, and many such bonds can be expected to persist even after pulping operations. Such issues are important with respect to separation of lignin from black liquor, since the polysaccharides tend to be more water-loving, and they may contain the readily dissociated carboxylic acids, as indicated in Table 1.

Table 1 also shows that ordinary phenolic groups can be expected to play a major role with respect to the properties of lignin present in black liquor. Notably, there are no strong acid groups, such as sulfonate or sulfate, listed in the table. This is despite the fact that such groups can play important roles in materials resulting from sulfite pulping processes (Sjöström 1989; Gellerstedt et al. 2013). Evidence of the importance of such groups in sulfite pulps was uncovered by Fatehi et al. (2016). Though these authors were able to precipitate some lignin by acidification of spent sulfite liquor, the majority remained soluble, which is consistent with the presence of strong acid groups, the dissociation of which is unaffected adjustment of $\mathrm{pH}$ within typical ranges.

Sulfur also has been found associated with lignin from kraft pulping. Gellerstedt et al. (2013) detected about 2 to $3 \%$ sulfur content in kraft lignin that had been separated from black liquor by sequential treatment with carbon dioxide and sulfuric acid, and about half of that amount was said to be molecularly bound to lignin moieties. Helander et al. (2013) found that most covalently bound sulfur in such cases was associated with low molecular mass compounds.

\section{Molecular mass}

The quantification of lignin's molecular mass poses challenges, and different results can be obtained depending on the type of lignin and the methods employed. Primarily due to different determination methods, there are only limited reliable data available on the molecular mass distribution of various lignins in black liquors during alkaline delignification. In practice, these data would be of great importance when considering the mass transfer aspects, but also with respect to the full-scale separation of lignin from different black liquors; for example, when predicting the lignin portion that can be separated by acid precipitation at different pHs (Pakkanen and Alén 2012; Kumar et al. 2016). As general trends, it is known that milled wood lignin preparations have weightaverage molecular masses of between 15,000 and $20,000 \mathrm{~g} / \mathrm{mole}$, which is four to five times that of kraft lignin (Glasser et al. 1983) and, on the other hand, that soluble hardwood lignins typically have slightly lower molecular masses than softwood lignins (Goring 1971). Few reported determinations also suggest that the weight-average molecular mass of soluble lignin from the sulfur-free soda-AQ cook of birch is somewhat higher than that of the corresponding kraft lignin (Lehto et al. 2015). Additionally, for example, it has been found (Glasser et al. 1983) that the weight-average molecular mass of soluble lignin in wheat straw soda-AQ black liquors is significantly higher than that originated from the wheat straw kraft pulping. This finding is useful when considering the effective production of sulfur-free lignin from alkaline black liquors by membrane techniques or acid precipitation. Based on physicochemical considerations, it seems that a suitable model for soluble lignin would be a compact microgel made up of crosslinked material, which is capable of limited swelling, rather than being a hard, solvent-impermeable sphere (Goring 1971). 
The molecular mass of lignin from black liquor has been studied by gel permeation chromatography. Helander et al. (2013) found that the results of such analyses depended on sample preparation. Weight-average molecular mass values ranged from $3525 \mathrm{~g} / \mathrm{mole}$ (acetylated lignins dissolved in tetrahydrofuran, THF) to $2071 \mathrm{~g} / \mathrm{mole}$ (non-acetylated lignins in THF) to $2005 \mathrm{~g} / \mathrm{mole}$ (alkaline aqueous analysis). All of these values were decreased substantially when evaluating the material passing through an ultrafiltration membrane having a cut-off of $1 \mathrm{kDa}$. Humpert et al. (2016) reported a molecular mass range of 1100 to $6500 \mathrm{~g} / \mathrm{mole}$ for lignin from black liquor from various sources. Pakkanen and Alén (2012) determined weight-average molecular mass values of 1900 to 4100 and 2200 to $2600 \mathrm{~g} / \mathrm{mole}$ for softwood and birch kraft lignin, respectively, using gel permeation chromatography without any pre-fractionation. The reported maximum weight-average molecular mass of soluble lignin from the sulfur-free soda-AQ cook of birch is 3300 to $4400 \mathrm{~g} / \mathrm{mole}$ (Lehto et al. 2015).

Kouisni et al. (2016) determined the weight-average mass values of several LignoForce lignins (softwood, eucalyptus, and other hardwoods) following acetobromination and elution through a GPC/UV system using BHT-stabilized THF as the mobile phase. The $M_{\mathrm{w}}$ of six softwood, four hardwood and three eucalyptus lignins from different mills ranged from 6000 to $12500 \mathrm{~g} / \mathrm{mole}, 2635$ to $6249 \mathrm{~g} / \mathrm{mole}$, and 2100 to 2700 $\mathrm{g} / \mathrm{mole}$, respectively.

\section{Solubility properties}

As will be described in more detail in later sections of this article, technologies that can be used to separate lignin from black liquor can be greatly affected by the extent to which the lignin is present in soluble or insoluble form, e.g. particles, colloids, or separate phases. From a fundamental standpoint, a solvent will be most able to dissolve a solute if there is a favorable match between four sets of parameters having to do with the hydrogen bond donation, hydrogen bond accepting, polarizability, and cohesive energy density (Marcus 1993). In practice, simplified analyses are more often applied, dealing with subsets of such parameters (Hansen 2007).

In the course of studying organosolv pulping, it was shown that native lignin from enzymatically hydrolyzed corn stalks is most soluble in liquid media having an ideal range of solvent attributes (Ye et al. 2014). Mixtures of about 15 to $35 \%$ water with THF, dioxane, or ethanol were advantageous to achieve high solubilization of lignin from enzymatically hydrolyzed cornstalks. The cited authors found that such results were consistent with a calculated Hildebrand solubility parameter of $13.7\left(\mathrm{cal} / \mathrm{cm}^{3}\right)^{0.5}$ for lignin. Earlier estimates by Goring (1971) for the Hildebrand solubility parameter of lignin were 10 to $11\left(\mathrm{cal} / \mathrm{cm}^{3}\right)^{0.5}$, and the best binary solvent systems for typical lignin were in the range 10.5 to $12.5\left(\mathrm{cal} / \mathrm{cm}^{3}\right)^{0.5}$. Yuan et al. (2009) showed that the composition of extracted lignin from eucalyptus varied depending on the character of the medium; lignin with higher content of polysaccharides and non-condensed phenol-propane units tended to be present in the extract of solvents having higher Hildebrand parameter values. Wang et al. (2010) found that eucalyptus lignin fractions of increasing molecular mass were extracted by solvents having increasing Hildebrand values and hydrogen bonding capacity. Conversely, Weerachanchai et al. (2014) found that the Hildebrand values of solutions tended to approach that of lignin with the increasing solubilization of beech wood lignin. 
With respect to the polar character of lignin, two factors of great importance are the value of $\mathrm{pH}$ and lignin-polysaccharide complexes. Both of these topics were already discussed in connection with Table 1. Briefly stated, lignin's solubility in water decreases with decreasing $\mathrm{pH}$, which is consistent with increasing protonation of phenolic groups (especially in the $\mathrm{pH}$ range 12 to 9) and carboxylic acid groups (especially in the $\mathrm{pH}$ range 7 to 2). In addition, the multiple $-\mathrm{OH}$ groups (typically two per sugar monomeric unit) will contribute to polarity, rendering the lignin more soluble in water. There are no practical differences in terms of the oxygen-containing functional groups that exist in kraft, soda, and soda-AQ lignins for the same feedstock. As an example, Gellerstedt et al. (2013) have reported only some differences between spruce and birch kraft lignins; the total amount of aromatic hydroxyl groups 4.1 (spruce) and 4.3 (birch) $\mathrm{mmol} / \mathrm{g}$, total amount of aliphatic hydroxyl groups 3.1 (spruce) and 1.7 (birch) $\mathrm{mmol} / \mathrm{g}$, and total content of sulfur 1.4 to 1.6 (spruce) and 2.2 to 2.4 (birch) \%. Similar to kraft lignins, soda lignins are hydrophobic even though high amounts of carboxylic acid groups in non-wood material make these lignins somewhat less hydrophobic than kraft wood lignins (Lora 2008).

\section{Polysaccharides in Black Liquor}

Sugar-related compounds may be present in black liquor as monomer units, as oligomers, or as polysaccharides. The origin of most such compounds is the hemicellulose component, which is more water-soluble, generally lower in mass, and lacks the extensively crystalline character of cellulose. Lisboa et al. (2005) studied black liquors from kraft pulping of Eucalyptus globulus and found between 2.9 and $7.3 \%$ of the black liquor solids to be comprised of polysaccharides that could be precipitated in the presence of dioxane. The average molecular mass of the xylan component (which is dominant in Eucalyptus) was about 18,000 g/mole. According to Alén et al. (1985a,b) and Niemelä et al. (1985), extensive degradation of glucomannans takes place during the heating-up period of a conventional kraft cook. The same authors observed 28 to $36 \%$ hydroxyl acids content based on the dry mass of black liquor.

\section{Monomers in Black Liquor}

The availability of extractives-related compounds in a pulp mill system is strongly dependent on the wood species used for pulping, the method and time of storing logs and chips, and the growth conditions of the trees (Alén 2011). For example, the typical content of extractives in native softwoods is less than $5 \%$ of the wood dry solids (Alén 2000a; Holmbom 2011). Of these, about 40\% consists of resin acids (e.g. abietic and pimaric acids), about $10 \%$ free fatty acids (e.g. oleic, linoleic, and pinolenic acids), about $40 \%$ esters of fatty acids (e.g. fats and waxes), and about $10 \%$ others (e.g. mostly neutral substances, "nonsaponfiables") (Frederick 1977; Back and Allen 2000). In contrast, hardwoods from temperate zones contain normally less than $4 \%$ of the wood dry solids and this fraction consists of about $20 \%$ free fatty acids, about $55 \%$ esters of fatty acids (fats), and about $25 \%$ others. During kraft pulping, the volatile turpentine components are chemically stable, but the fatty acid esters are hydrolyzed almost completely (Alén 2000b). Due to this saponification with the simultaneous neutralization of aliphatic carboxylic acids, extractives also consume cooking chemicals.

\section{Viscosity Issues}

The viscosity of black liquor has the potential to impede various processing steps, especially at high solids levels. The viscosity of softwood black liquors is mostly due to 
its lignin content and molecular weight (Zaman and Frinke 1995, 1996), while in the case of hardwoods the presence of xylan content enhances the effect of molecular weight (Söderhjelm et al. 1992; Söderhjelm and Sågfors 1994). As discussed by Frederick (1997), black liquor viscosity rises in an accelerated fashion with increasing solids content, but the viscosity tends to be reduced with increasing sulfidity, especially in the case of hardwoods. Black liquor viscosity tends to be reduced with increasing alkali (especially in the case of softwood liquors) up to a certain point, beyond which it rises again (U-shape curve) (Milanova and Dorris 1990). Black liquor viscosity is also influenced by the increased boiling point, which is a consequence of increasing concentration of electrolytes in black liquor as water is removed by evaporation. Also, the viscosity decreases with the passage of time of heating the black liquor at temperatures over $180{ }^{\circ} \mathrm{C}$ without (Kiiskilä and Virkola 1987; Nikkanen 1993) or with oxygen addition (Louhelainen 2003), which is presumably due to continued molecular breakdown. This is of importance especially in the case of non-wood black liquors, which cannot be evaporated to as high a dry solids content as wood black liquors. The determination of black liquor viscosity has been carried out by many researchers (Oye et al. 1977; Söderhjelm 1988; Milanova and Dorris 1990; Söderhjelm et al. 1992; Zaman and Fricke 1994, 1995, 1996; Roberts et al. 1996; Dutka et al. 2004).

Moosavifar (2006) conducted tests to find out how softwood black liquor viscosity might be impacted by removal of some of the lignin. In general, lignin removal resulted in lower viscosity, when solids content and temperature were held constant. Accordingly, Gellerstedt et al. (2013) assumed that black liquor would have a lower viscosity after removal of some of the lignin by acidification.

\section{Emulsified Lignin}

A further issue that needs to be kept in mind when considering the separation of lignin from black liquor is that some of the content of black liquor may be present as some form of suspension, colloid, or emulsion. Evidence of the presence of fine particulate material in spent pulping liquor was shown, for example, in work by Fatehi et al. (2016), who studied neutral sulfite semichemical pulping. The present review of the literature did not find corresponding published research for kraft or soda pulp lignins. Pirttinen et al. (2007) stated that lignin particles can be stabilized in suspension due to the presence of fatty acid soaps in pulping liquor. It was noted that upon acid precipitation of such soaps, redissolution can be very difficult. When the $\mathrm{pH}$ was lowered to 2.5 or below, particle size analysis revealed the presence of particulate matter. Rudatin et al. (1989) found evidence of molecular-self association of lignin entities in black liquor samples that has been partly acidified. Likewise, Fritz et al. (2017) reported increasing self-association of softwood kraft lignin within alkaline solutions with increasing concentration of monovalent salt. Lake and Blackburn (2016), in their patent document refer to "dispersed lignin", suggesting that not all of it was fully solubilized, though no quantitative information was provided. After addition of acid, the presence of solid matter becomes readily apparent; for instance Namane et al. (2015) attributed slow lignin cake dewatering after lowering the $\mathrm{pH}$ of black liquor to the precipitation of small particles of lignin. The black liquor was from kraft pulping of a hardwood-softwood mixture. However, this statement is contrary to other cases, in which colloidal destabilization generally has resulted in more rapid dewatering of softwood kraft lignin (Ohman and Theliander 2007; Helander et al. 2013). 


\section{FACTORS AFFECTING LIGNIN SEPARATION FROM BLACK LIQUOR}

\section{Overview}

By adjustment of chemical and physical conditions, the lignin and certain other components of black liquor can be induced, either in part or almost completely, to come out of solution and precipitate. This section will consider factors that appear to influence such changes and discuss how such effects are related to the chemical composition of lignin and other components of the mixture. According to Kihlman (2016) there are three main processes by which lignin can be separated from black liquor: acidification, ultrafiltration, and electrolysis. Of these, acidification has been by far the most implemented and also the most directly affected by lignin's solubility and phase behavior. However, as will be argued in a later section, related issues will also be important in understanding and optimizing conditions for ultrafiltration-based lignin recovery.

Before reviewing factors contributing to phase changes, it is worth bearing in mind a potential complicating factor, which is irreversibility. In particular, lignin cannot be readily dissolved again if it has been acidified and then dried. This aspect was shown most distinctly by Lindström (1979), who used an isolated softwood kraft lignin (Indulin ATR) in the study. Figure 1 is a replotting of his data, showing how the concentration of lignin that was in dissolved form in the filtrate was dependent on the degree of dissociation of acidic groups on the material. Fresh, never-dried lignin gave the upper line, showing a high level of solubility throughout the range of dissociation considered (related to the $\mathrm{pH}$ ). The lower plotted line was obtained from the same kind of lignin, but after freeze-drying. Only at the highest levels of dissociation was the latter sample capable of full solubilization, or at least dispersion in sufficiently small particles to pass through a Millipore ${ }^{\circledR}$ filter membrane.

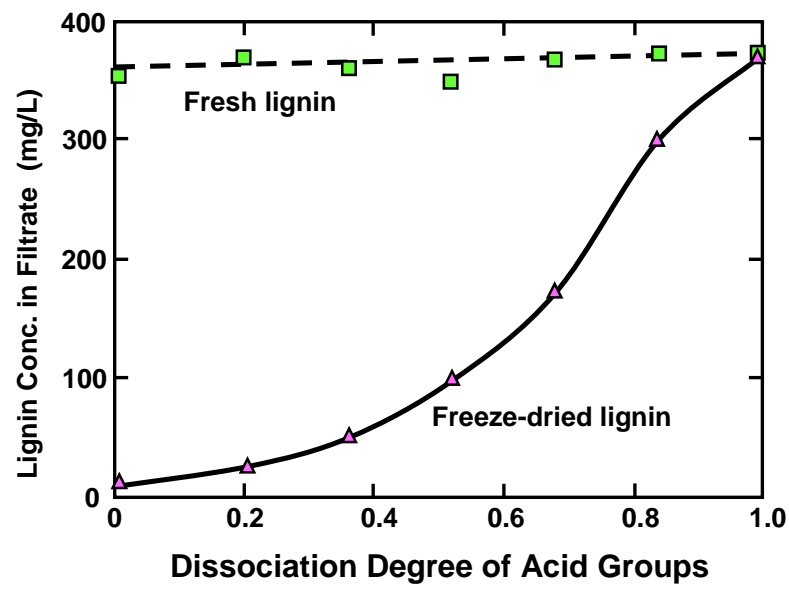

Fig. 1. Example of the irreversible nature of lignin phase behavior. Upper curve: lignin content in filtrate from fresh lignin; lower curve: lignin content in filtrate from freeze-dried lignin of the same type. Data replotted from Lindström (1979)

Norgren et al. (2001) reported related results, which can be expected to be very dependent on process conditions. Phase behaviors from soluble to precipitated states, upon changing of temperature, were observed to be irreversible. Though such phenomena have been rarely reported, any tendency of "once precipitated, never more to be soluble," is likely to have practical implications. 
Another point to make at the outset of a discussion of coagulation is the importance of the key variables $\mathrm{pH}$ and ionic strength. Very high levels of $\mathrm{pH}$, as in the case of untreated black liquor, can be expected to immediately lead to the formation of the corresponding insoluble hydroxide species upon addition of coagulants having divalent or trivalent cations (Monhemius 1977). In addition, the best-established theories for predicting coagulation have mainly been tested under relatively low ionic strength conditions.

\section{$\mathrm{pH}$ and $p K a$ Values}

In 1942 a kraft pulp mill in Charleston, SC, USA began to produce lignin as a side product by acidification of kraft lignin (Kouisni et al. 2016; Durruty et al. 2017b), and the process there has continued operation up to the present, yielding a stated 20,000 tons per year of lignin (Gellerstedt et al. 2013). Though the process details are not publicly disclosed, this example clearly shows not only that $\mathrm{pH}$ can have a big effect on lignin solubility, but also that the process can be run successfully at industrial scale.

Effects of $\mathrm{pH}$ on lignin separation from black liquor are shown, for instance, in Fig. 2, which is a replotting of data reported by Uloth and Wearing (1989a). The black liquor in the cited work was from the kraft pulping of spruce (50\%), lodgepole pine (35\%), balsam fir (10\%), and Douglas fir (5\%), all softwoods. It is clear from the graph that the yield of precipitated lignin increased with decreasing $\mathrm{pH}$. Furthermore, the results are consistent with the existence of two $\mathrm{pH}$ ranges in which changes in $\mathrm{pH}$ had large effects on lignin yield. One such range was above $\mathrm{pH} 7$, and the $\mathrm{pKa}$ values in Table 1 suggest that those effects can be attributed to the progressive protonation of phenolic - OH groups. A second transition had a maximum slope at a $\mathrm{pH}$ of about 3 or 4 , and Table 1 suggests that those changes can be attributed to protonation of hydroxy carboxylic acid groups, i.e. mainly products of hemicellulose breakdown in which the carboxylic acid is at a carbon adjacent to a $\mathrm{C}-\mathrm{OH}$ hydroxyl group.

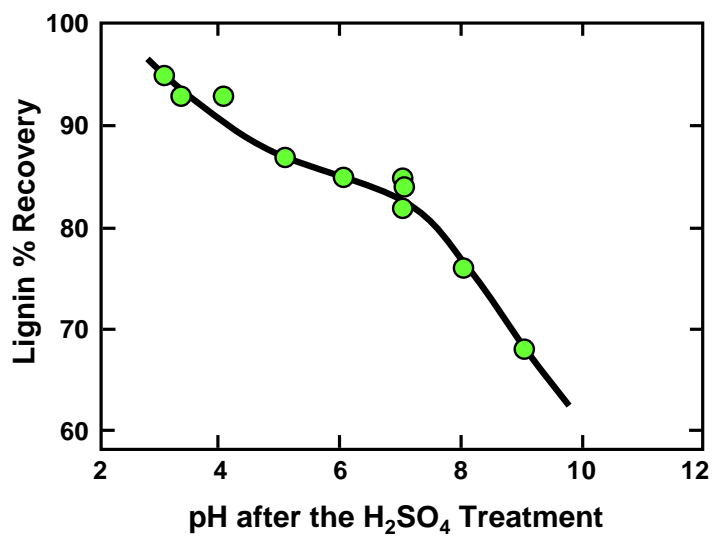

Fig. 2. Effect of $\mathrm{pH}$, achieved by addition of strong acid to kraft black liquor, on the yield of precipitated lignin. Data are replotted from the work of Uloth and Wearing (1989a).

It is notable that commonly presented representations of lignin's typical structure (e.g. see Sjöström 1993; Frederick 1997; Norgren and Eklund 2014) contain few or no carboxyl groups. It follows that the polysaccharide component either must be covalently bonded as lignin-polysaccharide complexes, adsorbed onto the lignin, or merely present together with the lignin material. 
Tomani et al. (2012) reported that different amounts of acid are needed to neutralize the alkalinity of black liquor from pulping of different wood species. A higher content of carboxylate groups in hardwood black liquor, due to the type and amount of hemicelluloses (Wallmo 2008), can be expected to increase the consumption of acid during precipitation.

Results consistent with the general trends shown in Fig. 2 have been widely reported (Nyman et al. 1986; Wienhaus et al. 1990; Sun et al. 1999; Norgren et al. 2001; Mussatto et al. 2007; Ohman and Theliander 2007; Toledano et al. 2010a,b; Moreva et al. 2011; Velez and Thies 2013; Zhu et al. 2014; Zhu and Theliander 2015; Zhu et al. 2016), though the $\mathrm{pH}$ ranges and yields have exhibited large shifts when comparing different studies.

As noted by Zhu et al. (2016), protonation of acidic groups associated with lignin results in colloidal instability, leading to aggregation and precipitation. A general takeaway from this diversity is that the materials within black liquor from different sources can have significant differences in colloidal behavior.

\section{Acid Type}

As described below, research involving both weak acids (mainly $\mathrm{CO}_{2}$ ) and strong acids has been reported as means of promoting the separation of lignin from the aqueous phase of black liquor. In both cases a key action of the acid is to protonate any phenolic functional groups, thereby rendering the some of the lignin moieties less soluble in water. But as a general rule, only the strong acids, represented most notably by sulfuric acid, are able to bring the $\mathrm{pH}$ low enough to protonate also the carboxylic acid functional groups associated with lignin. The type of acid used to lower the $\mathrm{pH}$ of black liquor can make a difference, not only in the resulting $\mathrm{pH}$ but also in the cost.

$\mathrm{CO}_{2}$

A key advantage of using $\mathrm{CO}_{2}$ is that it does not disturb the balance between $\mathrm{Na}$ and $\mathrm{S}$ in the recovery cycle (Wallmo 2008). Because there is abundant carbon dioxide present in the exhaust gasses in the smokestacks of alkaline pulping operations, $\mathrm{CO}_{2}$ can potentially be derived from these sources and used for at least the initial treatment of black liquor (Lake and Blackburn 2014; Kihlman 2016; Durruty et al. 2017b).

Studies have shown that $\mathrm{CO}_{2}$ can be effective for reducing the $\mathrm{pH}$ of black liquor to values in the approximate range of 7 to 10.5 (Tomlinson and Tomlinson 1946; Alén et al. 1979, 1985b; Weinhaus et al. 1990; Howell and Thring 2000; Ohman and Theliander 2001, 2007; Wallmo et al. 2007, 2009a,b; Nagy et al. 2010; Zhu and Theliander 2011, 2015; Velez and Thies 2013; Lake and Blackburn 2016; Kouisni et al. 2016; Kumar et al. 2016). Stocklosa et al. (2013) found that although $\mathrm{CO}_{2}$ readily reduced the $\mathrm{pH}$ to 9.5, the majority of softwood kraft lignin already became precipitated when the $\mathrm{pH}$ was lowered to a level between 10 and 11.1, which suggests that their specimen was mainly stabilized by phenolate functional groups having a $\mathrm{p} K_{\mathrm{a}}$ of about 10 or possibly higher (Table 2 ). The precipitation yield increases markedly at the higher carbonation pressures, especially at short carbonation times since $\mathrm{pH}$ is stabilized in a relatively short time at the higher pressures (Gray et al. 1953; Nikitin et al. 1963; Alén et al. 1979). Table 2 lists the final $\mathrm{pH}$ values achieved in various studies by addition of $\mathrm{CO}_{2}$ to black liquor. 
Table 2. Summary of $\mathrm{pH}$ Values and Lignin Yields Achieved by Addition of $\mathrm{CO}_{2}$ to Black Liquor

\begin{tabular}{|c|c|c|c|}
\hline Type of black liquor & $\begin{array}{l}\text { Lowest } \\
\text { pH } \\
\text { reached }\end{array}$ & $\begin{array}{l}\text { Reported } \\
\text { yield of } \\
\text { lignin }\end{array}$ & Literature reference \\
\hline Pine kraft pulping & 8 & 77 & Alén et al. 1979 \\
\hline Pine \& birch kraft \& soda pulping & 8.9 & 63 to 70 & Alén et al. 1985b \\
\hline Kraft pulping & 10.4 & - & Ball \& Vardell 1962 \\
\hline Non-wood soda pulping & 7.7 & 72 & Dhingra et al. 1952 \\
\hline Hardwood kraft pulping & 7 & 87 & Howell \& Thring 2000 \\
\hline Kraft pulping & 9.6 & - & Keilen et al. 1950 \\
\hline $\begin{array}{l}\text { Softwood, hardwood, eucalyptus } \\
\text { kraft }\end{array}$ & 9.5 & - & Kouisni et al. 2016 \\
\hline Birch soda-anthraquinone pulping & 9 & 59 & Kumar \& Alén 2014 \\
\hline Birch soda-anthraquinone pulping & 8.5 & 50 & Kumar et al. 2016 \\
\hline Black liquor (patent claims) & 9 to 10.5 & - & Lake \& Blackburn 2016 \\
\hline Eucalyptus kraft pulping & 9.3 & - & Merewether $1962 a$ \\
\hline Softwood kraft pulping & $\begin{array}{l}9.5 \text { to } \\
10.5 \\
\end{array}$ & - & Nagy et al. 2010 \\
\hline Softwood kraft pulping & 9 to 11 & 40 to 68 & Ohman \& Theliander 2007 \\
\hline Pine kraft and soda pulping & 9 & - & Pollak et al. 1944 \\
\hline Black liquor (patent claims) & 8.5 & - & $\begin{array}{l}\text { Tomlinson \& Tomlinson } \\
1946\end{array}$ \\
\hline Softwood kraft pulping & 9.5 & - & Velez \& Thies 2013 \\
\hline Softwood kraft pulping & 8.6 & 56 to 59 & Wallmo et al. $2009 a$ \\
\hline Kraft pulping & 7.7 & - & Weinhaus et al. 1990 \\
\hline
\end{tabular}

\section{Sulfuric acid}

Sulfuric acid is not only relatively inexpensive, compared to other acids, but it also becomes fully dissociated in solution, regardless of the $\mathrm{pH}$ value, i.e. it is classed as a strong acid. Alén et al. (1979) noted that sulfuric acid treatment was able to achieve a precipitated lignin yield of $90 \%$, which was regarded as favorable in comparison to a $77 \%$ yield that they were able to achieve with just $\mathrm{CO}_{2}$. The kraft black liquor was mainly from pine with about $8 \%$ birch content. Howell and Thring (2000) reported that generator waste acid, a byproduct from chlorine dioxide generator of kraft mill, can be used as a free source of sulfuric acid.

However, as reported by Wallmo (2008), the addition of sulfuric acid disrupts the mill's $\mathrm{Na}$ and $\mathrm{S}$ balance in the recovery cycle. Hence, even though sulfuric acid is cheaper than carbon dioxide on a mass (or molar) basis, in reality, it can lead to significantly higher chemical costs for a lignin plant if used in black liquor acidification.

Table 3 summarizes some key findings reported by researchers who used sulfuric acid as a precipitant. Ohman and Theliander (2007) noted that the yield rose from about $40 \%$ to about $70 \%$ as the $\mathrm{pH}$ was decreased from 10.8 to 8.8 . That range of $\mathrm{pH}$ was favored by the authors, since it yielded a more readily filterable lignin in comparison with higher $\mathrm{pHs}$, in addition to increasing the yield. The greater filterability is consistent with colloidal destabilization due to greater protonation of acidic groups at the lowered $\mathrm{pH}$ values. 
Table 3. Summary of $\mathrm{pH}$ Values and Precipitated Lignin Yields Achieved by Addition of Sulfuric Acid to Black Liquor

\begin{tabular}{|c|c|c|c|}
\hline Type of black liquor & $\begin{array}{l}\text { Reported } \\
\text { final pH } \\
\text { reached }\end{array}$ & $\begin{array}{l}\text { Reported } \\
\text { yield of } \\
\text { lignin (\%) }\end{array}$ & Literature reference \\
\hline Pine with $8 \%$ birch kraft pulping & 2 & 90 & Alén et al. 1979 \\
\hline Wheat straw soda pulping & 4 & - & Dominguez-Robles et al. 2016 \\
\hline Miscanthus sinensis soda pulping & 10 to 7.5 & $10^{*}$ & Garcia et al. 2009 \\
\hline Miscanthus sinensis soda pulping & $<4$ & $40^{*}$ & Garcia et al. 2009 \\
\hline Birch soda-anthraquinone pulping & 2 & 91 & Kumar \& Alén 2014 \\
\hline Birch soda-anthraquinone pulping & 2 & - & Kumar et al. 2016 \\
\hline Softwood kraft process & 2 to 3 & $70 \%$ & Lake et al. 2015 \\
\hline \multirow{5}{*}{$\begin{array}{l}\text { Brewer's spent grain soda } \\
\text { pulping }\end{array}$} & 6.0 & 16 & \multirow{5}{*}{ Mussatto et al. 2007} \\
\hline & 4.3 & 68 & \\
\hline & 3.2 & 79 & \\
\hline & 2.6 & 80 & \\
\hline & 2.2 & 81 & \\
\hline Softwood kraft, after $\mathrm{CO}_{2}$ acidific. & 3 & - & Nagy et al. 2010 \\
\hline Mixed softwood \& hardwood kraft & 9 & $83 \%$ & Namane et al. 2015 \\
\hline Eucalyptus globulus kraft & 2 & high & Neto et al. 1999 \\
\hline Unspecified kraft & 9 to11 & 40 to 70 & Ohman \& Theliander 2007 \\
\hline Softwood kraft \& nonwood soda & 2 & high & Sameni et al. 2016 \\
\hline Hemp \& flax, soda-anthraquinone & 5 & high & Surina et al. 2015 \\
\hline \multirow{2}{*}{ Softwood kraft, after skimming } & 9 & 67 to 77 & \multirow{2}{*}{ Uloth \& Wearing 1989a } \\
\hline & 4 & 93 to 95 & \\
\hline Pine and bamboo alkaline & 3.5 to 4 & $90 \%$ & Yang et al. 2003 \\
\hline $80 \%$ spruce, $20 \%$ pine kraft & 9.5 & 78 to 87 & Zhu \& Theliander 2015 \\
\hline
\end{tabular}

Notes: ${ }^{*}=$ Values reported by Garcia et al. (2009) appear to be relative to the total solids content of the black liquor, rather than the lignin content. It follows that the reported numbers should be multiplied by a factor between about 2 and 2.5 .

\section{Phosphoric and hydrochloric acids}

Dominguez-Robles et al. (2016) evaluated wheat straw soda pulping black liquor acidification with phosphoric acid, in comparison with parallel testing with sulfuric acid and hydrochloric acid. Target $\mathrm{pH}$ levels were 2 and 4 . Notably, the phosphoric acid gave the highest lignin yield. The authors judged the results obtained with a final $\mathrm{pH}$ of 4 to be more favorable, mainly because the cost of acid was about half what was required to reach a $\mathrm{pH}$ of 2 and the lignin yields and properties were similar at the two $\mathrm{pH}$ values. Structural differences in the precipitated lignin, when using phosphoric acid to reach the lower $\mathrm{pH}$, were attributed to the high concentrations of acid required. In addition it seems likely that the observed effects were attributable to higher ionic strength when phosphoric acid was used. Though hydrochloric acid can be used in lab studies, it is more expensive than sulfuric acid and also corrosive to stainless steel, which is the prevalent construction material within pulp and paper mills.

\section{Lignin precipitation with organic acids}

Namane et al. (2016) compared black liquor (from both hardwood and softwood pulping) acidification with formic, citric, and acetic acids, with sulfuric acid serving as a reference. A final $\mathrm{pH}$ of 4 was reached, based on the cited procedure (Namane et al. 2015). Precipitation was achieved in each case, and the resulting lignin precipitated by organic acids was low in sulfur content. Lignin precipitated with acetic and citric acids showed 
less weight loss during thermal decomposition compared to lignin precipitated with sulfuric or formic acids. Namane et al. (2016) make the case that organic acids (like $\mathrm{CO}_{2}$ ) do not disrupt the $\mathrm{S} / \mathrm{Na}$ elemental balance when lignin precipitation is incorporated into a kraft recovery cycle.

\section{Optimization of $\mathrm{pH}$ conditions}

Sometimes, depending on what kind of acid is utilized, there are many practical constraints that can influence decisions about what final $\mathrm{pH}$ value or values should be targeted when acidifying black liquor. Uloth and Wearing (1989), who used a combination of sulfuric acid with chlorine dioxide (presumably to oxidize residual sulfides and hydrosulfides), noted that attempts to reach $\mathrm{pH}$ values lower than 7 yielded extreme evolution of gas, including $\mathrm{CO}_{2}$ and $\mathrm{H}_{2} \mathrm{~S}$. In addition, the low-pH conditions resulted in very fine particles of precipitated lignin, which were difficult to filter. Likewise, Kouisni et al. (2016) noted that at $\mathrm{pH}$ values below 11 there is potential to release reduced sulfur compounds, unless specific measures are undertaken to avoid that result. Marton (1971) recommended a two-stage acidification as a strategy to achieve good filterability. In the first stage the black liquor is acidified with either $\mathrm{CO}_{2}$ or sulfuric acid to a $\mathrm{pH}$ of about 9 to 10 , and the precipitate is filtered. The precipitate is then resuspended in water and acidified with sulfuric acid to $\mathrm{pH} 2$ to 3 .

Gradients of progressively lower $\mathrm{pH}$ levels have been considered by some researchers as a means of separating the lignin into possibly useful fractions (Stoklosa et al. 2013; Kihlman 2016). For example, dos Santos et al. (2014) observed that decreasing the precipitation $\mathrm{pH}$ from 4 to 2 tended to increase the carboxylic acid content of the precipitated lignin. Such results are consistent with the principle that hydroxy carboxylic acid species can be expected to remain at least partly in their charged, more soluble form, until the $\mathrm{pH}$ is decreased below about 3.5 (Table 1). Such issues will be considered in greater detail when discussing various end-use possibilities for recovered lignin.

\section{Temperature}

Because various acidification technologies involve the use of pressurized chambers, the published literature includes consideration of temperatures both above and below the boiling point of water. Working at ambient pressure, Weinhaus et al. (1990), in their study of kraft black liquors, found that it was advantageous to precipitate the lignin in the temperature range of 60 to $80^{\circ} \mathrm{C}$, but then to raise the temperature if necessary to 80 ${ }^{\circ} \mathrm{C}$ for better filterability. Similar results were obtained by several researchers (Pollak et al. 1944; Keilen et al. 1950; Gray et al. 1953; Merewether 1962a; Ohman and Theliander 2007). Alén et al. (1979) observed that lignin precipitation tended to increase with increasing time as well as with increasing pressure of $\mathrm{CO}_{2}$ in pressurized systems. Velez and Thies (2016) investigated the effects of processing conditions, temperature, and pressure; three black liquors were evaluated, two from softwood and one from hardwood. An increased yield was obtained at higher acidification temperature, and the temperature also affected the molecular properties.

Tomlinson and Tomlinson (1946) claimed a process in which black liquor was acidified at a temperature of about $45^{\circ} \mathrm{C}$, which was found to be favorable for settling. But then the temperature was raised to $90^{\circ} \mathrm{C}$, which was favorable for separation of the viscous liquid from the water phase. Precipitation at temperatures above $76.7^{\circ} \mathrm{C}$, using a pressurized system, was claimed by Keilen et al. (1952). The advantage of such conditions was that the precipitated lignin remained in a liquid state, facilitating separation of two 
liquid phases that differ in density. Velez and Thies (2013) reported that the examined liquid-lignin specimens contained about 32 to $48 \%$ water. These authors proposed that the solvating ability of the water contributes to the liquid character of the lignin phase that separates upon addition of $\mathrm{CO}_{2}$ at high temperature. This approach of operating under pressure was adopted by Lake and Blackburn (2011, 2014), whose process involved reheating the lignin to considerably higher levels. The acidification process is exothermic, which also contributes to an increase in temperature. Kihlman (2016) assumed a $10{ }^{\circ} \mathrm{C}$ increase due to the heat of neutralization in such a process. The preferred resulting temperature has been stated as between 150 and $190^{\circ} \mathrm{C}$ (Lake and Blackburn $(2011,2014)$. A key advantage of such an approach is that immiscible liquid phases naturally tend to minimize their interfacial area, thus reducing any tendency for aqueous contaminants to remain entrained within or adsorbed upon particles of lignin. On the other hand, the liquidlignin phase obtained in the SLRP process from softwood pulping has been shown to contain 32 to $48 \%$ water by mass (Velez and Thies 2013).

\section{Black Liquor Solids}

The solids level of black liquor becomes raised in stages during multi-effect evaporation in a conventional kraft recovery system, so it makes sense to consider whether a certain solids content might be most favorable for lignin recovery by acidification. Alén et al. $(1979,1985 \mathrm{~b})$ found that the most effective separation occurred when the black liquor had been concentrated, by partial evaporation of the water, to a solids of about $30 \%$. At this dry solids content the separation of the tall oil soap is also effective and this soap can be removed from black liquor by skimming prior to liquor carbonation. Mesfun et al. (2014) made a similar assumption in their techno-economic modeling. A higher solids content can be regarded as an advantage because there is less volume to be acidified. On the other hand, the higher viscosity associated with higher solids can cause practical difficulties in such cases. Velez and Thies (2016) observed that black liquor with higher solids or higher inorganic content gave rise to higher amounts of ash in the isolated lignin. Moosavifar (2008) observed that lignin precipitated from black liquor of lower solids content tended to contain less sulfur.

\section{Coagulation by Cationic Additives}

Coagulation basics

As noted before, the principles governing coagulation mechanisms have been best established for low ionic strength conditions. Also, the high $\mathrm{pH}$ associated with black liquor, before acidification, can be expected to convert calcium and aluminum cations to the corresponding insoluble hydroxide forms. So the following discussion is not expected to be directly transferrable to some situations of primary interest to industry.

Studies have shown that addition of various cationic substances can be effective in bringing about destabilization of aqueous suspensions or solutions of lignin (Table 4). Such effects often can be attributed to reduction in the short-range repulsive forces between the negatively charged surfaces, i.e. the double-layer forces (Lindström 1979, 1980; Hiemenz and Rajagopalan 1997; Norgren and Edlund 2001, 2003; Ohman et al. 2007a; Hubbe and Rojas 2008). Addition of salt ions decreases the distance over which the repulsive forces extend between adjacent like-charged surfaces in the solution, which is the basis of the so-called DLVO theory (Derjaguin and Landau 1941; Verwey and Overbeek 1948). Another aspect is that multivalent cations, depending on their size, can form strong complexation with the negatively charged surfaces. The net result of these two effects can 
be a very strong dependency of coagulation on the valence of the cations, as can be expressed by the empirically-based Schulze-Hardy rule (Schulze 1882; Hardy 1899). This rule can be expressed as in Eq. 1,

$$
\mathrm{CCC} \propto z^{-6}
$$

where $\mathrm{CCC}$ is the critical coagulation concentration and $z$ is the valence of the ion opposite in charge to the surface.

Table 4. Studies in Which Metal Cations Were Used to Coagulate Lignin

\begin{tabular}{|c|c|c|c|c|c|}
\hline Valence & Ion & $\mathrm{pH}$ & $\begin{array}{l}\text { Concentration } \\
\text { (M) }\end{array}$ & Wood type & Citation \\
\hline \multirow[t]{7}{*}{1} & $\mathrm{Li}, \mathrm{Na}, \mathrm{K}$ & 3 to 8 & $10^{-3}$ to 1 & SW & Lindström 1980 \\
\hline & $\mathrm{Na}$ & 2 to 9.5 & $10^{-3}$ to 0.1 & NS & Moreva et al. 2011 \\
\hline & $\mathrm{Na}$ & 3.85 & 0.5 & SW & Norgren et al. 2001 \\
\hline & $\mathrm{Na}$ & 10.2 & 0.35 & SW & Norgren et al. 2002a \\
\hline & $\mathrm{K}, \mathrm{Na}, \mathrm{Cs}$ & 8 to 10 & 0.375 & SW & Norgren \& Edlund 2003 \\
\hline & $\mathrm{Na}$ & 12.8 & 0.008 & SW\&HW & Nyman et al. 1986 \\
\hline & $\mathrm{Na}$ & $\begin{array}{l}9.5 \text { to } \\
11\end{array}$ & * & SW & Zhu \& Theliander 2015 \\
\hline \multirow[t]{4}{*}{2} & $\mathrm{Ca}$ & 1 to 10 & $10^{-4}$ to $10^{-3}$ & SW & Dong et al. 1996 \\
\hline & $\begin{array}{l}\mathrm{Mg}, \mathrm{Ca}, \\
\mathrm{Ba}\end{array}$ & 3 to 7 & $10^{-4}$ to $10^{-2}$ & SW & Lindström 1980 \\
\hline & $\mathrm{Ca}$ & 2 to 9.5 & $10^{-3}$ to 0.1 & NS & Moreva et al. 2011 \\
\hline & $\mathrm{Ca}$ & 12 to 13 & $10^{-3}$ & SW & Norgren et al. 2001 \\
\hline \multirow[t]{4}{*}{3} & $\mathrm{Al}$ & 1 to 10 & $10^{-5}$ to $10^{-4}$ & SW & Dong et al. 1996 \\
\hline & $\mathrm{Al}, \mathrm{La}$ & 3 to 9 & $10^{-5}$ to $10^{-4}$ & SW & Lindström 1980 \\
\hline & $\mathrm{Al}, \mathrm{Fe}$ & 1 to 10 & $10^{-2}$ & NS & Garg et al. 2010 \\
\hline & Al & 2 to 9.5 & $10^{-5}$ to $10^{-3}$ & NS & $\begin{array}{l}\text { Moreva \& Chernoberezhskii } \\
2011\end{array}$ \\
\hline
\end{tabular}

Note: ${ }^{*}$ - The ionic strength was increased by either 10 or $20 \%$. SW $=$ softwood; HW = hardwood, NS = not specified

It is worth noting that the work of Zhu and Theliander (2015) listed in Table 4 involves much higher levels of ionic strength than most of the other reported work.

\section{Monovalent cation effects}

As shown in Table 4, precipitation of lignin from aqueous solution can be brought about by adding sufficient amounts of sodium ions or other monovalent cations. It can be seen that the concentrations of such ions as $\mathrm{Na}^{+}, \mathrm{K}^{+}$, and $\mathrm{Li}^{+}$needed to bring about coagulation of various $\mathrm{pH}$-near-neutral suspensions of lignin were in the range of $10^{-3}$ to 1 M. The wide range can be attributed to the very wide range of $\mathrm{pH}$ values considered in these studies. The value reported by Nyman et al. (1986) seems low relative to what was reported by other researchers at similarly high values of $\mathrm{pH}$; however, these authors essentially purified the kraft lignin by decreasing the $\mathrm{pH}$ to 3 with $\mathrm{HCl}$, washing, then purifying with ethanol, dioxane, and toluene treatment before redissolving it at $\mathrm{pH} 10 \mathrm{using}$ $\mathrm{NaOH}$. The purification steps may have removed components that otherwise would have helped to stabilize the material in solution.

The effects of monovalent salt concentration at $\mathrm{pH}$ values in the range 9.5 to 12.5 were studied by Norgren et al. (2002b). The greatest colloidal stability was observed at 
high $\mathrm{pH}$ and minimum ionic strength. Systems with higher $\mathrm{pH}$ were more likely to be able to tolerate a given level of salt without destabilization of the lignin.

While both the DLVO theory and the Schulze-Hardy rule imply that all monovalent cations ought to have equal effects, work by Norgren et al. (2003) showed that the effectiveness actually tended to follow a Hofmeister series. In general, monovalent cations having a larger radius were slightly more effective. An opposite relationship was found for the negative ions that were added in the same set of experiments. A key point to bear in mind, however, is that such effects tend to be minor in comparison to the effects of differing valences of the cations present.

Though most research related to coagulation has focused on aqueous systems, Leskinen et al. (2017) recently showed that salt addition can be used to induce precipitation of lignin, in nanoparticle form, from mixtures of THF and water.

\section{Divalent cation effects}

Dong et al. (1996) showed that addition of calcium ion markedly reduced the absolute value of zeta potential when added to lignin particle suspensions over a wide range of $\mathrm{pH}$ values. It is also clear from the work of Lindström (1980) and Moreva et al. (2011) that, for purposes of precipitating lignin particles from suspensions of near-neutral $\mathrm{pH}$, calcium ions were at least a factor of ten more effective than monovalent ions in bringing about coagulation. Earlier work using magnesium sulfate to coagulate black liquor after its acidification to $\mathrm{pH}=2$ was reported by Merewether (1962b).

\section{Trivalent cations, including aluminum}

Trivalent or higher valence cations, such as those of soluble aluminum species, have been found to be highly effective for destabilization of aqueous suspensions of lignin. Figure 3 shows replotted data from Lindström (1980) for commercial softwood kraft lignin; this is an excellent example to show the much greater coagulating power of multivalent cations, as predicted by the Schulze-Hardy rule.

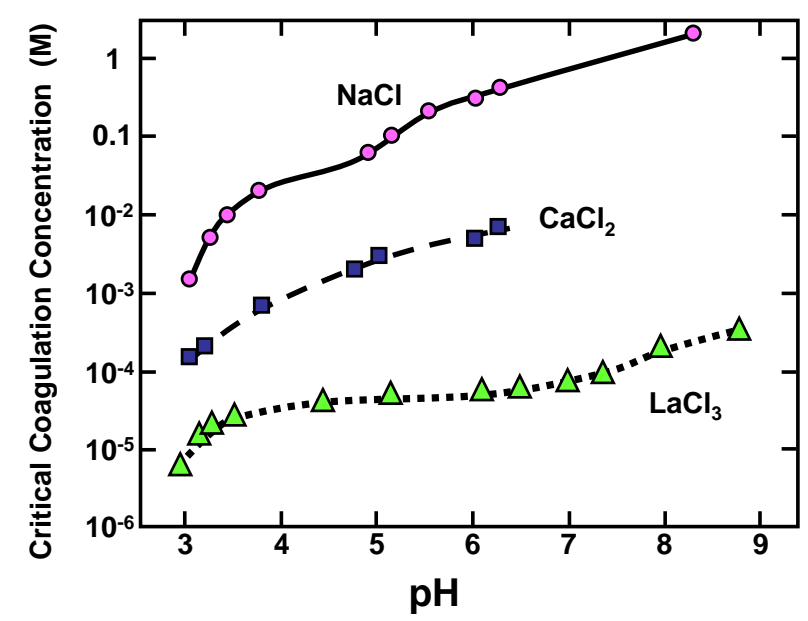

Fig. 3. Effects of cation valence and pH on the critical coagulation for precipitation of lignin

The reason that Lindström (1980) employed $\mathrm{LaCl}_{3}$ rather than $\mathrm{AlCl}_{3}$ in this series of tests was to simplify the chemistry; it is well known that Al has a very strong tendency 
to complex with $\mathrm{OH}^{-}$ions, forming a range of complex different species, depending on the pH (Exall and van Loon 2003; Bi et al. 2004).

Charge reversal has been observed by some researchers upon addition of soluble aluminum compounds to lignin suspensions (Lindström 1980; Dong et al. 1996; Garg et al. 2010; Moreva and Chernoberezhskii 2011). In related work, Rastegarfar et al. (2015) used electrocoagulation, by means of aluminum electrodes, to coagulate black liquor from soda pulping of straw. It is well known that electrocoagulation with such electrodes leads to the release of aluminum ions into the solution, thus causing the coagulation effect.

It is well known that much greater coagulating ability can be achieved if aluminum compounds are formulated so that the molar ratio of aluminum to $\mathrm{OH}$ is approximately 2 , corresponding to a composition that is popularly known as "poly-aluminum chloride" (PAC) (Exall and van Loon 2003; Bi et al. 2004). Unsurprisingly, PAC has been shown to be very effective for precipitation of black liquor (Amriani et al. 2015; Wang et al. 2015). Wang et al. (2015) also showed the strong coagulating effect of a high-charge quaternary polymer, poly(diallyldimethylammonium chloride) (polyDADMAC) for the precipitation of lignin from black liquor.

Despite the very promising results just cited for aluminum-based compounds, there is one very serious limitation with respect to the use of such coagulants for black liquor. That is, at the high $\mathrm{pH}$ of typical black liquor, the $\mathrm{Al}^{3+}$ and other cationic molecular species should be instantly converted to negatively charged aluminate ions, or possibly into neutral $\mathrm{Al}(\mathrm{OH})_{3}$ floc if the added amounts were enough to neutralize the $\mathrm{pH}$ (Bottero and Fiessinger 1989). Thus, it would appear that the most sensible usage of aluminum-based coagulants would be after the $\mathrm{pH}$ already had been reduced to about 5 or lower by addition of $\mathrm{CO}_{2}$ and sulfuric acid. It also would be of interest to find out whether aluminum compounds in the precipitated lignin were beneficial, or at least not harmful relative to the envisioned end-use of the lignin. Suitable experiments would need to be performed.

\section{Stirring}

Stirring or agitation is mentioned in some of the publications dealing with separation of lignin by acidification of black liquor. For example, the patent disclosure by Keilen et al. (1952) recommends an agitation "not substantially in excess of 2100" Reynolds number (implying turbulent flow) as a means of favoring a small particle size of droplets of lignin during the process of acid treatment. Keilen et al. (1950) has also stated that particularly when operating at temperatures above $80{ }^{\circ} \mathrm{C}$, the amount of agitation to which the liquor is subjected during the heating is critical (i.e., below 1500 Reynolds number). According to Wallmo (2008), increased stirring during precipitation tended to increase the rate of $\mathrm{pH}$ decrease, but the filtration resistance of the precipitate also increased. This was a bigger issue in the case of hardwood kraft black liquor, which may have been due to a higher content of hemicellulose.

After black liquor has been treated such as to bring about precipitation, certain publications suggest gentle agitation during the ensuing sedimentation. Presumably, such gentle agitation encourages collisions among droplets or particles of lignin, helping them to coagulate, while still allowing settling to occur. Howell and Thring (2000) recommended that agitation be "as low as possible" to allow settling for the lignin after black liquor treatment with waste acid from a chlorine dioxide generation process. Amriani et al. (2015) call for "slow stirring" at 50 revolutions per minute following a treatment with PAC. Kannangara et al. (2016) recommended to use low turbulent power mixing during coagulation to increase the filtration rate of precipitated lignin. Kouisni et 
al. (2016), when describing the LignoForce system, specify "gentle mixing" during the coagulation treatment.

Some other researchers have recommended agitation during the process of washing of precipitated lignin with dilute sulfuric acid solution. Thus, Gilarranz et al. (1998) recommended low agitation for a short time in order to optimize the subsequent washing with acid and water. Haddad et al. (2017a) likewise recommended agitation before a washing operation in the case of softwood kraft black liquor.

\section{Stabilizers}

As already mentioned, it is not always clear whether the lignin present in black liquor ought to be regarded as being dissolved or as being in a suspension or emulsion, depending on whether the temperature is high enough to melt it as droplets. In that context it is important to consider the likely importance of compounds capable of stabilizing such emulsions, whether those materials are already present in the black liquor, or whether they might be added later.

Some researchers have considered the effects of surfactants, i.e. molecules that have both a water-loving and an oil-loving part. For instance, Norgren and Edlund (2001) found that bile acids improved the colloidal stability of softwood kraft lignin suspensions. On the other hand, Norgren and Mackin (2009) later found that cationic surfactants could bring about an opposite effect, fast aggregation of softwood kraft lignin, leading to high yields of precipitated lignin. Another possible use of surfactant addition is to promote separation of rosin and fatty acid soaps (McGinnis et al. 1998).

The term steric stabilization means that a suspension or emulsion is stabilized by water-loving, relatively long-chain compounds on the surfaces of the dispersed entities (Tadros 1991; Hubbe and Rojas 2008). This can be due to adsorption or due to pendant chains. In such cases, the hydrophilic chains extending from the surfaces discourage close approach of the surfaces. Squeezing of the volume occupied by the extended chains is energetically unfavorable. Fritz et al. (2017) found that nonionic surfactants appeared to solubilize lignin, especially softwood kraft lignin, leading to a lower degree of selfassociation and lower turbidity. The relative ineffectiveness of salts to bring about coagulation of the lignin suspensions was attributed to steric stabilization by the surfactant.

\section{Polysaccharides and Lignin Stabilization}

Hemicellulose-related products, often in highly degraded and oxidized form, will be present in typical black liquor samples (Danielsson 2014). Nyman et al. (1986) proposed that typical aqueous lignin mixtures from pine kraft pulping behave as sterically stabilized colloids. Such an explanation is consistent with the observation (Durruty et al. $2017 \mathrm{a}, \mathrm{b})$ that addition of xylan to softwood black liquor can make the suspension more difficult to drain during filtration. The explanation for this is that in the filter cake the particles are more able to slide past each other, thus forming a denser layer that impedes the flow of water. The reported effect was more pronounced at higher $\mathrm{pH}$ (Durruty et al. 2017b), which is consistent with higher negative charges and more effective stabilization. Wallmo et al. (2009b) showed that the stabilization effect was reduced in cases where the hemicellulose content had been decreased before they applied acidification.

\section{Solubility Issues}

The phase-separation of black liquor can be understood in terms of solubility principles (Hansen 2007; Hubbe et al. 2015). The idea is that substances having similar or 
favorable polarity, polarizability, and hydrogen bonding capabilities are more likely to exist as a single phase. Such issues are known to become increasingly critical when dealing with high molecular mass solutes (Flory 1953). Giummarella et al. (2016) showed that the best solvents to dissolve softwood kraft lignin were generally those that are miscible with water, e.g. methanol. The best solvents for lignin also could be predicted based on the Hildebrand solubility parameters (related to cohesive energy density) and Hansen's red numbers (Hansen 2007).

Water-immiscible solvents have been shown to affect the colloidal stability and filterability of lignin from black liquor. Whalen and Tokoli (1968) showed that addition of small amounts of hydrophobic monomers eliminated the slimy, gelatinous, and hard-tofilter component of lignin, thus promoting its filtration and settling.

In principle, the solubility of lignin in water can be manipulated by changing its charged character. As already discussed, one of the ways to accomplish this is by changing the $\mathrm{pH}$. Thus, carboxylic acid functions, often associated with polysaccharide products either complexed to the lignin or adsorbed on it, will take on a negative ionic charge when the $\mathrm{pH}$ is near or above the corresponding $\mathrm{pKa}$ value, often near to 4 (see Table 1). Likewise, the phenolic groups will take on a negative charge as the $\mathrm{pH}$ becomes near or higher to 10, depending on the detailed chemistry. Liu and Luo (2010) showed that the stability of bamboo lignin in an aqueous medium could be improved by addition of citric acid, the adsorption of which would increase the negative charge of the surfaces.

\section{Interventions}

There are certain ways that the incoming material can be treated so as to achieve more favorable results when black liquor is acidified. The word "interventions" will be used here as a name for such treatments.

\section{Chip pre-extraction}

Extracting hemicellulose and other minor components from wood chips prior to pulping has been found to influence the composition of black liquor from brewer's spent grains (Mussatto et al. 2007). The byproducts of hemicellulose do not have as high a heating value as cellulose, and there are higher-value potential uses if the material can be extracted before pulping (Moshkelani et al. 2013). As already mentioned, hemicellulose removal can be expected to render the lignin easier to separate from the aqueous medium (Wallmo et al. 2009b; Ziesig et al. 2014a,b). In the cited work, polysaccharides were separated from black liquor by micro- and ultrafiltration before separation of the lignin by acidification with carbon dioxide.

\section{Black liquor oxidation}

The LignoForce process, which entails acidification of black liquor with carbon dioxide, includes an oxidation step, the purpose of which is to chemically transform any of the odoriferous reduced sulfur compounds to their corresponding oxidized forms, which are not volatile; this also reduces the amount of acid (carbon dioxide) required for the acidification of black liquor to precipitate lignin because the oxidation of reduced sulfur compounds, carbohydrates, and other organics consumes alkali in black liquor (Kouisni et al. 2012, 2014, 2016). Such a step is also called for in the process developed by Lake and Blackburn (2011). Advantages, in addition to reducing odors during processing, include better filterability and reduced product odor (Kouisni et al. 2012, 2016). Recently, Ozdenkci et al. (2017) included an oxidation step in an integrated biorefinery concept that 
included lignin recovery. Servaes et al. (2017) evaluated an oxidation step as a pretreatment of spent pulping liquor before membrane filtration. The general principle of such treatments was previously described by Tomlinson and Tomlinson (1946), Murray and Prakash (1976), and Uloth and Wearing (1989b) in the context of reducing the emission of odoriferous reduced sulfur compounds during processing. Tomlinson and Tomlinson (1946) found that oxidation increased the fusion point of lignin, affecting its handling properties at various temperatures.

\section{Plasma treatment}

Closely related to ordinary oxidation treatments, researchers have found favorable effects of plasma treatment of black liquor (Feng and Tian 2009). The cited authors fed hot, viscous black liquor concentrates into a nitrogen gas plasma jet prior to freezeseparation. Harmful gases such as $\mathrm{H}_{2} \mathrm{~S}, \mathrm{SO}_{2}$, and $\mathrm{SO}_{3}$ were eliminated.

\section{Silica precipitation at neutral $\mathrm{pH}$}

Yet another material worth separating from black liquor, especially in the case of grasses such as bamboo and wheat straw, is silica. Gilarranz et al. (1998) showed that this can be achieved by selective precipitation, using a $\mathrm{pH}$ high enough to avoid coprecipitation of the lignin present in the mixture. However, as noted by Mandavgane and Subramanian (2006), co-precipitation of lignin together with silica can make this approach difficult. The cited authors used an undisclosed flocculant in an attempt to achieve more specific destabilization of the silica content. Given the increasing importance of non-wood biomass for alkaline pulping, more research of this type can be justified.

\section{Operations}

Factors affecting the phase separation can be supplemented by various mechanical processes, making use of specialized equipment. Such approaches will be considered in this section.

\section{Separation of the acidified mixture by density}

After acidification of the black liquor, the means of promoting separation by density include gravitational sedimentation and centrifugation. Probably for reasons of simplicity, sedimentation approaches have been most often adopted in acid precipitation processes for lignin recovery (Tomlinson and Tomlinson 1946; Howell and Thring 2000; Mandavgane and Subramanian 2006; Norgren and Mackin 2009; Garg et al. 2010; Lake and Blackburn 2014; Leskinen et al. 2017). Centrifugation, as a means of achieving faster separation of lignin from black liquor, was demonstrated by Alén et al. (1985b), Mussatto et al. (2007), Liu and Luo (2010), and Namane et al. (2015).

\section{Filtering of solids}

A critical step in the processing of precipitated lignin is its filtration to increase the solids content (dewatering or cake) and to separate it from various components of the aqueous phase. This is most often done on a filter screen device (e.g. belt filter or filter press).

Alén et al. (1979) recommended heating of precipitated black liquor to $80^{\circ} \mathrm{C}$ before filtration. The stated reason was to avoid problems with fine dispersions and colloidal mixtures. Apparently the higher temperature favored an adherent nature of the particles, leading to formation of bulky, permeable filter beds. Weinhaus et al. (1990) and Howell 
and Thring (2000) found better filtration if acidification was done at a higher temperature. Garg et al. (2010) observed a similar effect in the case of lignin that had been precipitated with aluminum-based coagulants or ferrous salts, then filtered at either 25 or $95^{\circ} \mathrm{C}$.

The addition of salts has been shown to favor faster filtration in some cases (Helander et al. 2015; Durruty et al. 2017a). Such findings are consistent with the concepts of decreasing the range or strength of electrostatic repulsive forces between surfaces, thus encouraging sticking collisions between the particles and formation of bulky, permeable sediments. Accordingly, Durruty et al. (2017b) found that lower $\mathrm{pH}$ of the acidified material, which would be consistent with more complete neutralization of the carboxylic acid groups, favored higher rates of filtration, even in the presence of hemicellulose byproducts. Ohman and Theliander $(2001,2007)$ observed better filtration at higher ionic strength and lower $\mathrm{pH}$.

Kouisni et al. (2014) also found that oxidation favored subsequent filterability of the lignin, which will be considered next. In particular, the treatment increased the rate of filtration sufficiently that it was feasible to use one filter press instead of two, as is the case with the LignoBoost process. In the latter process, a first filter press is used to dewater the lignin cake, the cake is then suspended in dilute sulfuric acid and finally directed to second filter press at which it is washed with dilute sulfuric acid and water.

Ohman et al. (2007b) found that pre-concentration of black liquor with an ultrafiltration membrane made subsequent filtration more difficult; the reason is not fully understood. Haddad et al. (2016) observed fouling of a membrane when using a certain electrochemical approach that resulted in decreased $\mathrm{pH}$ (from about 12.5 to as low as 10.5) of black liquor. Wallmo et al. (2009a) found that filtration performance could be improved by holding the mixture for a "conditioning period" before filtration.

\section{Separation by affinity}

In addition to density, the relative affinity for water is another attribute that can serve as a way to promote separation of lignin from aqueous solution. The principle of differing affinity is used, for instance, when tiny bubbles of air are used to selectively float hydrophobic particles so that they can be skimmed from the water surface as a froth (Edzwald 2010; Jamaly et al. 2015; Saththasivam et al. 2016). The present search of the literature revealed only one study, the work of Macfarlane et al. (2009), which pursued such an approach for separation of lignin from water. Rapid removal of the lignin from the water phase was promoted by increasing temperature (in the range from freezing to about $\left.30^{\circ} \mathrm{C}\right)$ and increased pressure to create the bubbles $\left(\mathrm{N}_{2}\right)$.

\section{MEMBRANE TECHNOLOGIES}

\section{Membrane Filtration Overview}

Although membrane-induced separation of lignin from black liquor is influenced by many of the same factors as the acid-induced separation, as described in the preceding main section, the optimized chemical conditions tend to be very different. As will be shown in this section, membrane separation methods often work well under conditions favoring solubility, or at least colloidal stability of the lignin in the mixture. Jönsson et al. (2008), Humpert et al. (2016), and Kevlich et al. (2017) have provided reviews of membrane technology as it has been studied for the recovery or fractionation of lignin from black liquor and wastewater. Niemi et al. (2011) considered membrane separation in 
combination with cooling crystallization as a means of isolating multiple compounds from black liquor.

Research by membrane separation of lignin in black liquor also has been used to shed light on the association of the molecules in solution (Rudatin et al. 1989). It was shown that the amount of lignin retained on an ultrafiltration membrane (molecular mass cut-off 300,000 Daltons) was a function of the $\mathrm{pH}$ of the solution within the range $14>\mathrm{pH}$ $>10$. To account for this, the cited authors proposed that lignin moieties self-associate due to such influences as hydrogen bonding, hydrophobic character, or even association of opposite charges in specific cases. Junker (1941) may have been the first to report evidence of such self-association upon addition of monovalent ions at $\mathrm{pH}$-neutral conditions.

As has been shown in many studies, the class of membrane process that can be effective for retaining lignin, while allowing passage of water, salt, and monomeric compounds is called "ultrafiltration". Such a membrane can have pore sizes suitable for retaining macromolecules in the range from one-thousand to one-million grams per mole (Zeman and Zydney 2017). Based on estimated pore diameter, available membrane filter media can be classified as follows (Khulbe et al. 2008): reverse osmosis, < $1 \mathrm{~nm}$; nanofiltration, 1 to $5 \mathrm{~nm}$; ultrafiltration, 2 to $100 \mathrm{~nm}$, and microfiltration 100 to $2000 \mathrm{~nm}$. The composition can be either polymeric (e.g. polysulfone) or ceramic. Membranes typically have a recommended pressure range to avoid excessive fouling (Peter-Varbanets et al. 2009). By applying pressure, the membranes can be used effectively to concentrate the polymer solution, while allowing passage of solution that is contains only the low-mass components of the mixture. Ultrafiltration has been applied to varying black liquors for different purposes as reported, for example, by Hill and Fricke (1984), Alén et al. (1986), Lin (1992), Sevastyanova et al. (2014), and Zhu et al. (2016).

Though membrane separation processes can be efficient and cost-effective in many cases, there are two key limitations: First, such processes get increasingly difficult to operate as the concentration of the retained material increases. For example, Humpert et al. (2016) suggested a terminal concentration of the lignin solids, after ultrafiltration, of $285 \mathrm{~g} / \mathrm{L}$. Second, the flux of permeate passing through a membrane tends to fall during continued usage due to such fouling phenomena as pore plugging and cake formation (Fane and Fell 1987; Hubbe et al. 2009; Shi et al. 2014). Indeed, membrane fouling has been reported in studies related to black liquor (Jin et al. 2013; Mattsson et al. 2015; Haddad et al. 2017a-c). Mattsson et al. (2015) used an innovative dynamic gauging test to study softcake fouling by precipitated softwood kraft lignin. It follows that any attempt to implement membrane separation needs to place emphasis on (a) optimizing the ultimate solids content, (b) finding appropriate uses or further processing steps for lignin-rich concentrated retentate, and (c) developing effective cleaning and rejuvenation treatments for used membranes. One possibility could be to acidify the lignin-rich retentate, thus bringing about precipitation of the lignin. Future research would be needed to determine whether or not there are important advantages of carrying out the membrane separation before such acidification.

In general, ultrafiltration appears to be well suited for separation of aqueous solutions containing intermediate levels of dissolved polymeric matter (Zeman and Zydney 2017). For the perspective of lignin recovery, this suggests two likely favorable applications. First, ultrafiltration can be used as a means to exclude lignin from the outfall of wastewater treatment plants (Hubbe et al. 2016). Second, it could be used for concentrating black liquor, possibly as an alternative to evaporation. Such a concept has been offered as a commercial process by New Logic International, Inc. (New Logic 1999). 
The technology also was evaluated in a 2016 study at Lund University in Sweden (Lund 2016).

\section{Solubility Factors Affecting Membrane Separation}

It is well known that the relative solubility of lignin is affected by $\mathrm{pH}$, ionic strength, temperature, and the presence of cosolvents with water. In the case of $\mathrm{pH}$, two studies specified that high values of $\mathrm{pH}$ were employed during nanofiltration. Arkell et al. (2014) recorded a pH of 13.4, whereas the review article by Humpert et al. (2016), citing two sources, gives a $\mathrm{pH}$ range of 13 to 14 . At such $\mathrm{pH}$ values, almost all phenolic groups, including the hemiacetalic phenolic groups (Table 1), will be in their charged form. Also, since the $\mathrm{pH}$ is very much higher than the $\mathrm{p} K_{\mathrm{a}}$ values of carboxylic acids, any of those groups also will be in their dissociated, charged form, thus contributing to the solubility. Such high solubility can be expected to facilitate permeation, as well as molecular size selection, through an ultrafiltration membrane.

A quite different recommendation about $\mathrm{pH}$ was reported in one case where weak black liquor was intentionally destabilized prior to filtration. Helander et al. (2013) observed increasing rates of filtration with increased ionic strength. Dead-end filtration was carried out with a membrane having a cut-off of 1000 Daltons (see later discussion). The authors found that reducing the $\mathrm{pH}$ caused more material to precipitate, which was regarded in the study as a favorable outcome. It appears that the reported investigation optimized conditions such as to achieve unstable colloidal conditions, leading to a porous and easily filterable cake of materials resting on the membrane.

\section{Type of Primary Membrane}

When specifying the pore-size category of membranes for use as the primary membrane in lignin separation, most studies have opted for ultrafiltration, as opposed to such options as microfiltration, nanofiltration, or reverse osmosis (used to allow permeation of water, while holding back almost everything else, including monomeric ions). Studies using ultrafiltration are listed in Table 5.

Pore size, which is most often expressed as the "cut-off" based on the molecular mass of typical protein molecules (Zeman and Zydney 2017), is one of the key decisions that need to be made when using membranes to separate mixtures. As illustrated in Fig. 4, there is often a strong relationship between the retained amount and the estimated pore size.

Keyoumu et al. (2004) found that permeate from the finest pore size ultrafiltration membrane that they considered (cut-off 1000 Daltons) contained relatively pure phenolic lignin. Both softwood and hardwood kraft lignins were studied. Manttari et al. (2015) carried out nanofiltration of acidified permeate from an ultrafiltration process of separating softwood kraft black liquor. By such means they were able to collect precipitated lignin. However, they found that the ultrafiltration step had an adverse effect on the flux through the nanofiltration membrane after the acidification.

The general findings of studies included in Table 5 indicate that ultrafiltration can be used to retain a major fraction of lignin in black liquor, but that much of the ligninrelated matter passes through such membranes, even when the molecular weight cut-off is at the low end for the membrane category. As can be expected, lower cut-off filters led to higher retention values, where the retained material all was classified as "lignin" in of the cited studies. 
Table 5. Studies Reporting Use of Ultrafiltration Membranes to Process Black Liquor, Retaining Lignin

\begin{tabular}{|c|c|c|c|}
\hline $\begin{array}{l}\text { Cut-off } \\
\text { values } \\
\text { (kDa) }\end{array}$ & $\begin{array}{l}\text { Lignin } \\
\text { retention (\%) }\end{array}$ & Key observations & Literature reference \\
\hline 20 & 10 & $\begin{array}{l}\text { Ultrafiltration helped subsequent } \\
\text { nanofiltration to remove } \\
\text { hemicellulose. }\end{array}$ & Arkell et al. 2014 \\
\hline $5,15,50$ & - & $\begin{array}{l}\text { Higher cut-off gave somewhat purer } \\
\text { eucalyptus kraft lignin, but still high } \\
\text { inorganics present. }\end{array}$ & Costa et al. 2018 \\
\hline 15 & 35 to 45 & $\begin{array}{l}35 \% \text { retention of softwood kraft lignin } \\
\text { was observed in most cases, except } \\
\text { a batch condition }(45 \%) \text {. }\end{array}$ & Holmqvist et al. 2005 \\
\hline $1,5,15$ & $\begin{array}{l}67,55,47 \mathrm{HW} \\
68,64,57 \mathrm{SW}\end{array}$ & $\begin{array}{l}\text { The low-mass lignin was highly } \\
\text { phenolic. Both softwood and } \\
\text { hardwood lignins were studied. }\end{array}$ & Keyoumu et al. 2004 \\
\hline$\overline{1}$ & 75 & $\begin{array}{l}\text { Acid compounds passed through the } \\
\text { membrane and could be fractionated, } \\
\text { from two softwood kraft lignins. }\end{array}$ & Manttari et al. 2015 \\
\hline $\begin{array}{l}0.75,2,3 \\
4,5\end{array}$ & $\begin{array}{l}89,88,75,94 \\
82\end{array}$ & $\begin{array}{l}\text { Removal of inorganics and organic } \\
\text { acids from lignin was demonstrated. } \\
\text { Spruce chips were pulped with } \\
\text { carbonate and } \mathrm{Na}_{2} \mathrm{CO}_{3} / \mathrm{O}_{2} \text { stages. }\end{array}$ & Servaes et al. 2017 \\
\hline $5,10,15$ & $20(15 \mathrm{kDa})$ & $\begin{array}{l}\text { The different Miscanthus soda pulp } \\
\text { lignin fractions showed compositional } \\
\text { differences. }\end{array}$ & Toledano et al. 2010a \\
\hline $5,10,15$ & - & $\begin{array}{l}\text { Ultrafiltration yielded retained } \\
\text { Miscanthus soda pulp lignin relatively } \\
\text { free of hemicellulose. }\end{array}$ & Toledano et al. $2010 \mathrm{~b}$ \\
\hline 5,15 & 30,20 & $\begin{array}{l}\text { Filtration under pressure at } 135-145 \\
\text { oC was feasible. Both softwood and } \\
\text { hardwood kraft liquors were studied. }\end{array}$ & $\begin{array}{l}\text { Wallberg \& Jönsson } \\
2006\end{array}$ \\
\hline $4,8,20$ & $80,67,45$ & $\begin{array}{l}\text { The retained softwood kraft lignin was } \\
\text { much purer and free of sulfur. }\end{array}$ & Wallberg et al. 2003a \\
\hline 15 & 30 & $\begin{array}{l}\text { Multivalent cations were retained in } \\
\text { the softwood kraft lignin, presumably } \\
\text { due to association. }\end{array}$ & Wallberg et al. 2003b \\
\hline $1,5,15$ & - & $\begin{array}{l}\text { The softwood kraft lignin fractions } \\
\text { from ultrafiltration showed different } \\
\text { acidification results. }\end{array}$ & Zhu et al. 2016 \\
\hline
\end{tabular}

An unusual option was explored by Ooi et al. (2016), who studied "emulsion liquid membranes" for separation of kraft lignin in wastewater. The membrane was prepared by dissolving a cationic surfactant and a nonionic surfactant (sorbitan monooleate) in kerosene, with a sodium bicarbonate solution and an alcohol. Rather than being a conventional membrane, it appears that the surfactants together served as the walls of a stabilized emulsion, in which a bicarbonate aqueous solution was the internal phase. The authors proposed that the kraft lignin passed through the membrane into the interior of the stabilized droplets. Although the word "membrane" was used by the authors, it is not clear how such a system can be used to efficiently separate lignin from an aqueous mixture. 


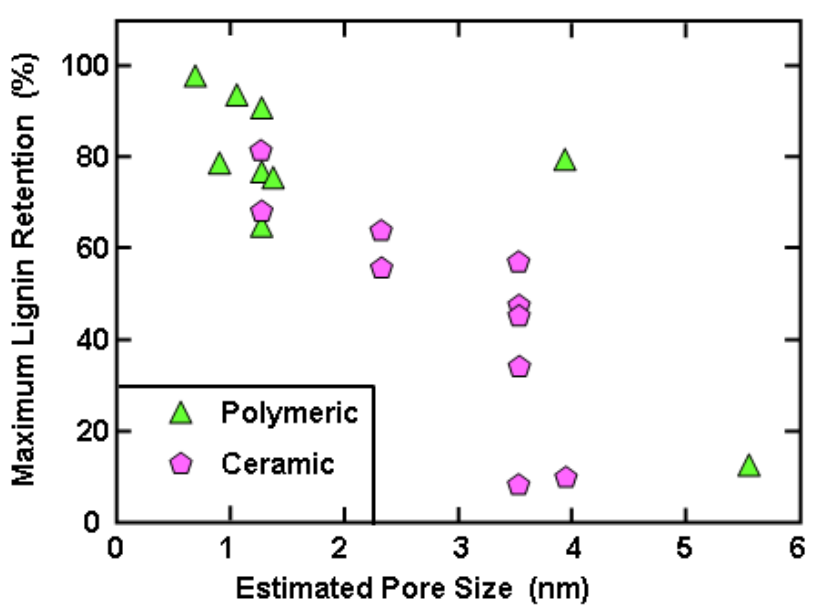

Fig. 4. Compilation of data for percentage retention of lignin as a function of estimated pore size in polymeric and ceramic ultrafiltration membranes (data replotted from Kevlich et al. 2017)

\section{Membrane Material}

Different kinds of materials are used in the construction of membranes, and the most significant distinction appears to be between polymeric and ceramic membranes. Based on published articles, it appears that ceramic membranes generally have performed as well as polymeric membranes (Wallberg et al. 2003b; Keyoumu et al. 2004; Holmqvist et al. 2005; Wallberg and Jönsson 2006; Toledano et al. 2010a; Arkell et al. 2014; Servaes et al. 2017). De and Bhattacharya (1996) suggested that certain polymeric membranes would be intolerant of the very high $\mathrm{pH}$ of typical black liquor; they showed that membrane filtration could be carried after $\mathrm{CO}_{2}$ treatment to reduce the $\mathrm{pH}$ to 7.5. However, no other publication dealing with black liquor processing expressed concern about $\mathrm{pH}$-intolerance.

\section{Pre-membrane}

In principle, the performance of a membrane can be influenced by carrying out a preliminary stage of filtration with a coarser membrane. De and Bhattacharya (1996) and Jönsson et al. (2008) used a sequence of ultrafiltration and nanofiltration. According to De and Bhattacharya (1996), the combination improved filtration in the second process.

\section{Electrolysis and Electrodialysis}

Electrolysis can be used to treat black liquor even in the absence of a membrane (Cloutier et al. 1993, 1994, 1995; Blanco et al. 1996; Negro et al. 2005; Ghatak 2009a,b; Ghatak et al. 2010). Cloutier et al. (1995) reported that deposition of lignin onto the anode could be avoided by keeping the $\mathrm{pH}$ high. This approach has potential to regenerate $\mathrm{NaOH}$ at the same time separating some of the lignin. Negro et al. (2005) were able to minimize fouling of the anode with lignin deposition by use of a Pt electrode and a high current density. In the work by Ghatak and coworkers, wheat straw and sugarcane bagasse lignin accumulated at the anode and hydrogen was evolved at the cathode. The chemical oxygen demand of the mixture was gradually consumed during continued application of the electric field (Ghatak 2009). The separated lignin was found to have a relatively low methoxyl content and a higher aromatic content (Ghatak et al. 2010).

Jin et al. (2013) demonstrated the separation of lignin from black liquor using a membrane-assisted electrochemical process. The $\mathrm{pH}$ was lowered to 4.7 , leading to lignin 
precipitation at the anode. Simultaneously, sodium hydroxide was recovered at the cathode. Other products included hydrogen and oxygen. However, precipitation of lignin on the anode tended to impede the reaction.

Haddad et al. (2017a-c) reported lignin separation from softwood kraft black liquor using an electro-dialysis process. The process resulted in a drop of $\mathrm{pH}$, bringing about the precipitation of lignin. The electrochemical procedure achieved the separation with less chemical addition, and $\mathrm{NaOH}$ could be recovered. By using pulses of applied voltage it was possible to reduce fouling while recovering a relatively high lignin yield (Haddad et al. 2017b). Similar approaches to apply electrolysis to black liquors have been reported by Mishra and Bhattacharya (1984, 1987), Arulanantham and Shanthini (1997), and Kumar and Alén (2014).

\section{Membrane Process Operation}

Trans-membrane pressure

The flux through a membrane, at constant transmembrane pressure, tends to decrease during usage due to fouling (Fane and Fell 1987; Shi et al. 2014). When processing black liquor, Jönsson et al. (2008) reported that the rate of fouling could be reduced by keeping the transmembrane pressure below a critical value.

\section{Cleaning of membrane}

Periodic cleaning of membranes has been recommended as a suitable way to deal with fouling and the resulting flux decline. Costa et al. (2018) recommended a 0.1 to 0.2 $\mathrm{M} \mathrm{NaOH}$ solution at a temperature of $40{ }^{\circ} \mathrm{C}$. Holmqvist et al. (2005) reported favorable results when using a proprietary alkaline product for membrane cleaning after ultrafiltration of black liquor. Wallberg and Jönsson (2006) developed the cleaning procedure further, and they implemented an initial rinsing with permeate, which was followed by $0.5 \% \mathrm{NaOH}$, and finally by use of the same cleaning agent specified by Holmqvist et al. (2005). Such alkaline cleaning media can make sense based on the fact that the black liquor components initially all were stable (soluble or at least colloidally suspended) at the very high $\mathrm{pH}$ of typical black liquor.

In the case of an electrochemical membrane separation process, a pulsed electric field might be used for such cleaning (Haddad et al. 2016). Haddad et al. (2017c) found that effective cleaning could be achieved with either $\mathrm{NaOH}$ solution or fresh diluted black liquor.

\section{WAYS TO GAIN VALUE BY SEPARATING LIGNIN}

Though the main focus of this review has been on factors and processes that are effective for the separation of lignin from back liquor, one of the important issues to consider is the different uses to which such lignin can be put. Clearly, the different processes of separation can result in large differences in purity, dryness, and other factors that might effect different end-use strategies. This section will consider publications dealing with applications of the lignin itself, the further refining of black liquor components to more completely isolate valuable compounds, the debottlenecking of pulp manufacturing plants, and finally, alternative options to recover process chemicals to be used in alkaline pulping. 


\section{Lignin's Value by Itself}

Recovered lignin, depending on its solids level, can have positive value as a fuel (Kannangara et al. 2012), and other potentially more valuable uses can be compared relative to the economics of lignin's use as a fuel. In Sweden there are several projects and start-up companies, such as Renfuel, that are considering the use of lignin as raw material for production of biodiesel (Löfstedt et al. 2016; Back 2018).

In principle, there are higher-valued uses for which the lignin may be used, as has been discussed elsewhere (Johansson 1982; Pye 2006; Gellerstedt et al. 2013; Souto et al. 2015; Teguia et al. 2017). As noted earlier, kraft lignin has been made commercially available for many years at a production rate of about 20,000 tons per year (Gellerstedt et al. 2013) and possibly higher at present. Current lignin capacities at various mills are estimated as 25,000 tons per year (Domtar Plymouth, LignoBoost), 50,000 tons/year (Stora Enso Sunila, LignoBoost), and 10,500 tons/year (West Fraser Hinton Alberta, LignoForce). Lignin-based products have included carbon fibers, activated carbon, and the phenolic component of phenolic adhesives, as a UV-light absorbent, and surfactants (lignosulfonates), among others (Norgren and Edlund 2014). According to Teguia et al (2017), one of the most promising uses for recovered kraft lignin is as a component of phenolic resins. For instance, work by Jiang et al. (2018) showed a high efficacy of phenolated lignin in the preparation of thermoset adhesives.

Major challenges related to many potential uses of kraft lignin are due to impurities and the diversity of chemical structures that it contains. As a first step in addressing such issues, there may be an advantage of just utilizing the fraction that can be precipitated by addition of $\mathrm{CO}_{2}$. Due to their low solubility at $\mathrm{pHs}$ intermediate between the $\mathrm{p} K_{\mathrm{a}}$ values of phenolic groups and carboxylic groups (Table 1), such fractions can be expected to contain less carbohydrate matter compared to when precipitation is brought about by addition of strong acid and further reduction of the $\mathrm{pH}$. However, as described specifically in the LignoForce system, strong acid can be used to wash lignin precipitated at a higher $\mathrm{pH}$, thus allowing metal ions to be washed free of the material (Uloth and Wearing 1989a; Ziesig et al. 2014a). It is understood that such treatment also has been incorporated into the LignoBoost and SLRP systems. Further testing will need to be done, in various potential areas of lignin application, to determine whether such purified forms of kraft lignin can compete successfully with other forms of lignin, such as enzymatic hydrolysis lignin (Rinaldi et al. 2016).

Another practical problem faced by potential users of industrial lignin is batch-tobatch variation in such properties as molecular mass and elemental composition. Important progress has been achieved in fractionation of industrial lignin into fractions having narrow and more predictable properties. Cui et al. (2014) achieved such results by first solubilizing softwood kraft lignin in acetone, then adding increasing levels of hexane to the acetone solvent phase. Jiang et al. (2017) reported related work with softwood kraft lignin starting with a methanol-acetone solution, then using addition of different amounts of ethyl acetate and a mixture of ethyl acetate and petroleum ether, and pure petroleum either. In each step the solvent was partially evaporated before adding the next solvent system.

Carbon fibers are often mentioned as a potential usage of recovered lignin (Gellerstedt et al. 2013; Ziesig et al. 2014b; Souto et al. 2015; Österberg et al. 2017). However, a very high quality of carbon fiber is required in order to be able to compete in that market, and thus far kraft lignins have not yielded sufficient uniformity and strength of the resulting fibers. Thus, Teguia et al. (2017) suggest that lignin from organosolv 
pulping is much more likely to be commercially important for production of resin components. Ziesig et al. (2014b) suggested that the quality of carbon fiber production from black liquor-sourced lignin could be greatly improved by washing at a low $\mathrm{pH}$ of 1.5 , thus displacing most of the metal content. It is unclear, however, whether or not such washing would render the kraft lignin competitive with other starting materials used for carbon fiber production, e.g. polyacrylonitrile (Yusof and Ismail 2012).

\section{Further Fractionation (Biorefining)}

The term "biorefining" implies that cellulosic raw materials are processed in such a way that their chemical components can be isolated efficiently and that at least some of the isolated components can be employed for a high-value function (Moshkelani et al. 2013; Rinaldi et al. 2016). The topic is worth briefly considering here, since lignin can be included as part of a refining scheme in which various numbers of components are isolated. In a broader context, the term biorefining sometimes is employed even if the fractionation is rather minor, such as just isolating some of the hemicellulose and tall oil fractions, to be used for purposes other than their fuel value (Huang et al. 2010).

There are a number of compounds that can be immediately recovered from black liquor. To begin with, the "tall oil" component is commonly skimmed from the surface of black liquor, usually after it has been partly concentrated by evaporation (Johansson 1982; McGinnis et al. 1998; Aro and Fatehi 2017). The tall oil, which consists of fatty acids, terpenes, resin acids (in the case of softwood pulping), and unsaponifiables can be used as the source of components for many adhesives, inks, and other industrial products (Johansson 1982; Zinkel and Russell 1989). Tall oil also can be a feedstock for biodiesel production (Lee et al. 2006). A company called SunPine presently satisfies $2 \%$ of Sweden's demand for diesel fuel by using such an approach (SunPine 2015). Another high-value (but relatively low world consumption) compound from lignin is vanillin, the source of vanilla flavor (Kaur and Chakraborty 2013; Mota et al. 2016). In principle, the extractive compounds will tend to float upon acidification of black liquor, whereas precipitated lignin will tend to settle, due to the densities of the materials. However, there appears to be a need for research concerning the efficient separation and maximization of yields of the two classes of organic compounds.

As shown earlier, besides lignin, large amounts of aliphatic carboxylic acids are formed in the kraft process, and their partial recovery is an interesting alternative to using them as fuel (Sjöström 1983; Alén et al. 1989; Alén 2011, 2014, 2015, 2018; Kumar 2016). The basic idea behind this approach is that about two thirds of the total heat produced by the liquor originates from lignin and only one third stems from the remaining constituents, mainly these acids. Their recovery is a complicated separation problem and has, so far, only been solved on a laboratory scale. According to a simplified scheme, after the recovery of tall oil skimmings and later lignin by carbonation, the sodium salts are liberated by sulfuric acid. After recovery of volatile formic and acetic acids by evaporation, a crude hydroxy acid fraction is obtained. A rough fractionation of acids, resulting in a "low-molarmass acid mixture" of glycolic, lactic, and 2-hydroxybutanoic acids, and "high-molar-mass acid mixture" of 3,4-dideoxy-pentonic, 3-deoxy-pentonic, xyloisosaccharinic, and glucoisosaccharinic acids is possible by alternative techniques. Aliphatic acids can be used as single components (volatile acids) or as more or less purified mixtures (hydroxy acids) in a number of applications.

\section{Debottlenecking of Pulp Production Facilities}


Recovery boilers, which incinerate the organic pulping liquors and enable the regeneration of pulping chemicals, are expensive to build and cannot easily be retrofitted to increase their capacities (Uloth and Wearing 1989a; Wallmo et al. 2007; Kannangara et al. 2012). As pulp and paper facilities continually attempt to expand their production rates, the recovery boiler often becomes the limiting factor in the overall production capacity of a pulp mill. A useful strategy in such situations may be to remove some of the lignin from the black liquor, thus decreasing the heat load of the boiler (Axelsson et al. 2006; Wising et al. 2006; Moshkelani et al. 2013). Extensive amounts of lignin cannot be removed from black liquor without jeopardizing the proper operation of the recovery boiler. Maximum lignin recovery ratios ranging from 9.5 to $50 \%$ have been reported in the literature (Loutfi et al. 1991; Vakkilainen and Välimäki 2009; Välimäki et al. 2010). Though there will be a penalty in terms of the amount of steam generated from the recovery boiler, this can often be made up with extra steam generated from the hog-fuel boiler (or power boiler). Also, some modern pulp and paper mills have a surplus of energy on account of the black liquor recovery system. A life cycle assessment study by Culbertson et al. (2016) found that such debottlenecking of a pulp and paper mill facility can be expected to reduce the overall adverse environmental impact. In the cases considered, removal of some of the lignin from the black liquor before returning it to a recovery boiler can provide a higher overall production rate of pulp when the boiler capacity is at its maximum. More extensive discussion of such issues is provided by Kannangara et al. (2012) and Gellerstedt et al. (2013).

To avoid disrupting the balance between sodium and sulfur in a typical kraft recovery system, $\mathrm{CO}_{2}$ is the only feasible acid that can be used at an industrial scale to bring about phase separation. Other acids, such as $\mathrm{H}_{2} \mathrm{SO}_{4}$ can be used later to fully protonate the precipitated lignin that will not be returned to the boiler. The fully protonated lignin, when filtered and rinsed, will have low ash content. $\mathrm{HCl}$ also can be used in the laboratory to treat already-precipitated lignin, except that the chloride ion is corrosive to stainless steel, which is commonly used in industrial processing equipment.

The optimum proportion of lignin to be removed from the recovery process at a given pulp and paper facility can be expected to depend on many factors. A balance needs to be maintained between the supply and demand for steam-generated power. For example, Cubertson et al. (2016) assumed that about $5 \%$ of the total lignin would be separated during the acidification step and that the rest of the lignin would be returned to the recovery boiler as black liquor.

\section{LignoBoost system}

The LignoBoost process was jointly developed by the research organization Innventia and Chalmers University in Sweden (Tomani 2010; Gellerstedt et al. 2013). Two production-scale implementations of the LignoBoost process had been completed by Valmet corporation as of 2016 (Kihlman 2016). Work by Hu et al. (2016) showed that the lignin produced from softwood kraft black liquor by the LignoBoost process at the Plymouth, NC, USA pulp mill or Domtar is very similar to the well-known Indulin AT product, which presumably comes from the Charleston, NC production facility of Westrock. If the recovery boiler capacity is the limitation for increasing pulp production, then by removing some of the lignin from the black liquor, the overall capacity for pulp production can be increased (Tomani et al. 2011; Helander et al. 2015). The basic process steps of the LignoBoost system are diagrammed in Fig. 5 (Gellerstedt et al. 2013). The first step is acidification to a $\mathrm{pH}$ of about 10 with use of carbon dioxide gas (Wallmo et al. 
2009a,b; Zhu and Theliander 2011; Gellerstedt et al. 2013; Zhu et al. 2014). Filter cake resulting from this initial acidification is reslurried, at which point the $\mathrm{pH}$ is further reduced with sulfuric acid to a $\mathrm{pH}$ in the range 2 to about 4 (Durruty et al. 2017b). Ziesig et al. (2014a,b) observed that a further reduction of the final $\mathrm{pH}$ to about 1.5 could be beneficial to minimize the ash content of the precipitated lignin. The acidified lignin slurry is then fed to a second filter press in which it is washed with dilute acid and water to produce a purified lignin cake of high solids content (50 to 60wt\%). According to Ohman et al. (2007), the reslurrying process prevents excessive $\mathrm{pH}$ and ionic strength gradients in the filter cake while washing. Such $\mathrm{pH}$ and ionic strength gradients may cause dissolution of lignin, which leads to partial plugging of the filter cake and inefficient washing. By reslurrying the cake, more efficient washing can be achieved, thus producing low ash lignin.

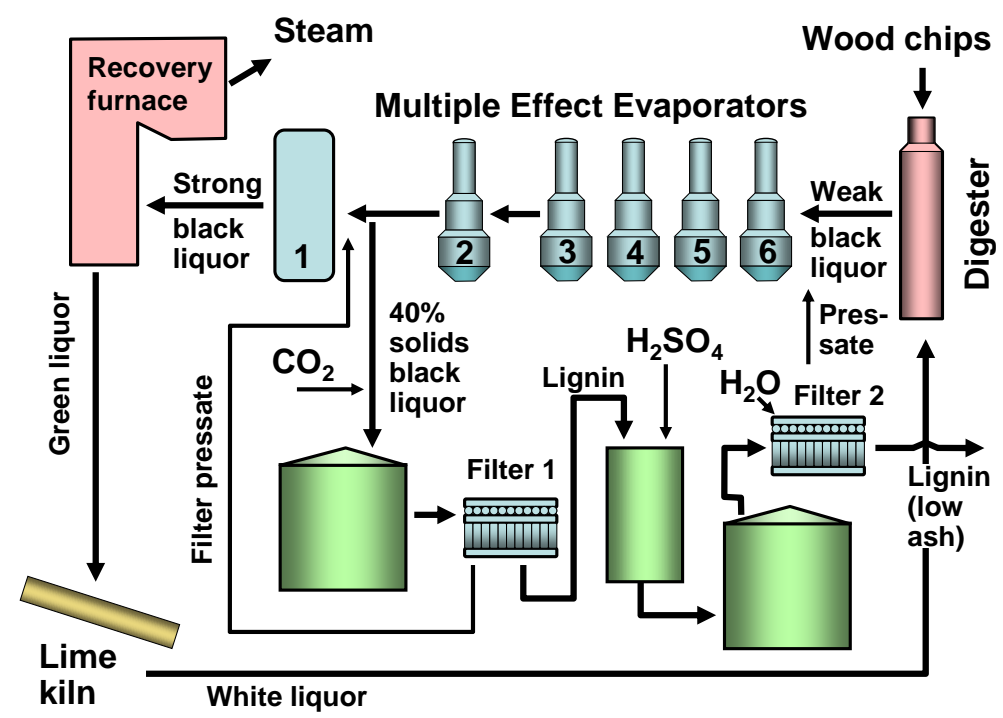

Fig. 5. Schematic diagram of the LignoBoost system (new figure based on concept by Gellerstedt et al. 2013)

\section{LignoForce system}

The LignoForce system was developed in Canada by FPInnovations, with construction of one commercial-scale facility by NORAM (Kannangara et al. 2012). The West Fraser Hinton Alberta plant was started in 2016. Main features of the LignoForce process are shown schematically in Fig. 6. A key feature of the LignoForce process is an oxidation step in which the black liquor is treated with oxygen to convert hydrogen sulfide and any other reduced sulfur species to safe and non-odorous compounds. Oxygen is added at $80{ }^{\circ} \mathrm{C}$, which not only oxidizes the volatile sulfur compounds but it also results in improved filterability of lignin during the lignin cake dewatering step as well as the subsequent acid washing and water washing steps (Kouisni and Paleologou 2014a). Since oxidation reactions are highly exothermic, this leads to an increase in temperature, which in turn leads to conditions favorable for lignin colloidal particle nucleation and particle growth. Then, pressurized $\mathrm{CO}_{2}$ is injected to reduce the $\mathrm{pH}$ to about 9 to 10 , causing the lignin to precipitate at about 65 to $75^{\circ} \mathrm{C}$ as solid particles (Kouisni et al. 2012, 2014a,b, 2016; Kouisni and Paleologou 2014a,b). Coagulation and aging happen at 60 to $65^{\circ} \mathrm{C}$, and 
the resulting lignin precipitate is filtered and pressed. Optionally, this low-odor, highsolids lignin product (lignin in sodium form) can be sold for applications in which a highsodium content is not a problem or, in fact, is preferred (e.g. phenolic resins and activated carbon). If a purified, low-ash lignin product is required, then the cake can be washed with sulfuric acid and water on the filter press to reduce the ash content to the range of 0.1 to $0.7 \%$. The pressed lignin cake has a solids content of 50 to $60 \mathrm{wt} \%$. According to Kouisni et al. (2012), the precipitated lignin from oxidized black liquor has larger particle sizes, which is desirable in obtaining higher filtration rates. Furthermore, the oxidation reduces the downstream $\mathrm{CO}_{2}$ and sulfuric acid requirements of the process. The reduction in $\mathrm{CO}_{2}$ consumption can be explained by the fact that oxidation of sulfide to sulfate and organics (e.g. sugars) to organic acids (e.g. sugar acids) consumes residual alkali in black liquor. The reduction in sulfuric acid consumption can be explained by the improved dewatering of the cake that occurs during lignin slurry filtration.

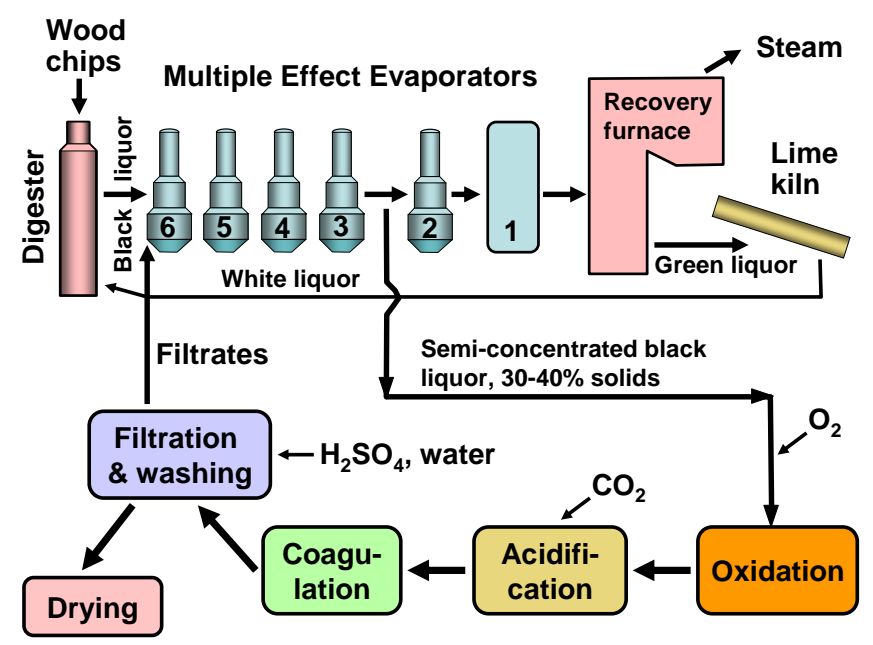

Fig. 6. Schematic diagram of the LignoForce process

\section{SLRP system}

The Sequential Liquid-lignin Recovery and Purification (SLRP) system was developed at Clemson University in South Carolina, USA and patented by Lake and Blackburn $(2011,2016)$. The system has been further discussed by Lake and Blackburn (2014), Lake et al. (2015), and Kihlman (2016). The technology is built upon a concept introduced by Tomlinson and Tomlinson (1946). A distinctive feature of the SLRP system is a higher temperature, allowing the acidification and separation to be accomplished above the melting point of hydrated lignin. The pressurized conditions employed make it possible to heat the mixture sufficiently so that precipitated lignin behaves as a free-flowing liquid rather than as a "gummy" material (Tomlinson and Tomlinson 1946). Velez and Thies (2016) state the temperature range as 100 to $150{ }^{\circ} \mathrm{C}$ at 500 to $800 \mathrm{kPa}$. Separation is by gravity, and the need for filtration is postponed to the washing step. A diagram of the main critical steps in shown in Fig. 7.

As shown in the figure, acidification is initiated with $\mathrm{CO}_{2}$, which is used to reduce the $\mathrm{pH}$ to about 9 to 10.5 at a claimed pressure between 50 and $200 \mathrm{psig}$ (345 to $1480 \mathrm{kPa}$ ) (Lake and Blackburn 2016). After separation by gravity, sulfuric acid is added to the lignin phase to further depress the $\mathrm{pH}$ to about 2 to 3 . This second acidification causes the release of $\mathrm{CO}_{2}$ and $\mathrm{H}_{2} \mathrm{~S}$, which could be recycled to the previous acidification stage, which can 
decrease the overall consumption of $\mathrm{CO}_{2}$ by about $18 \%$ (Kihlman 2016). Such release also would be expected in the case of the LignoBoost system; however, recycling is more complicated due to the operation at lower pressure. The LignoForce system involves addition of sulfuric acid at the filtration step; collection of gases at that point would probably be more difficult.

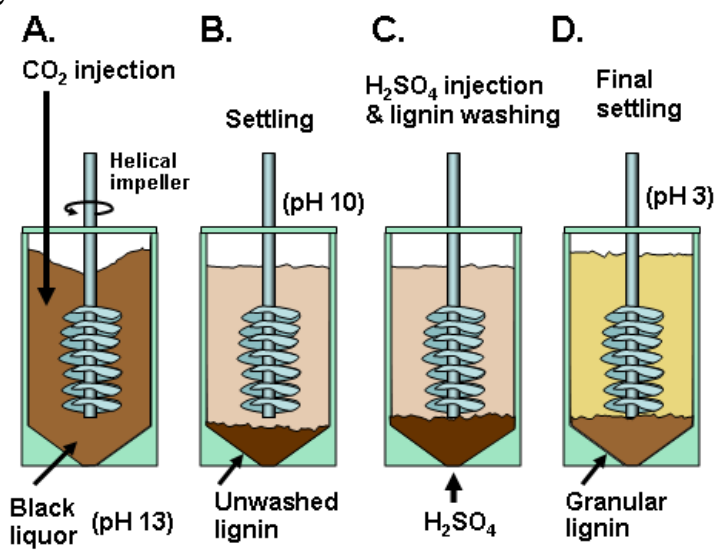

Fig. 7. Schematic diagram of the SLRP system for recovery of lignin from black liquor

Figure 8, which is based on a diagram by Velez and Thies (2016), shows a scheme intended for continuous operation of the SLRP system.

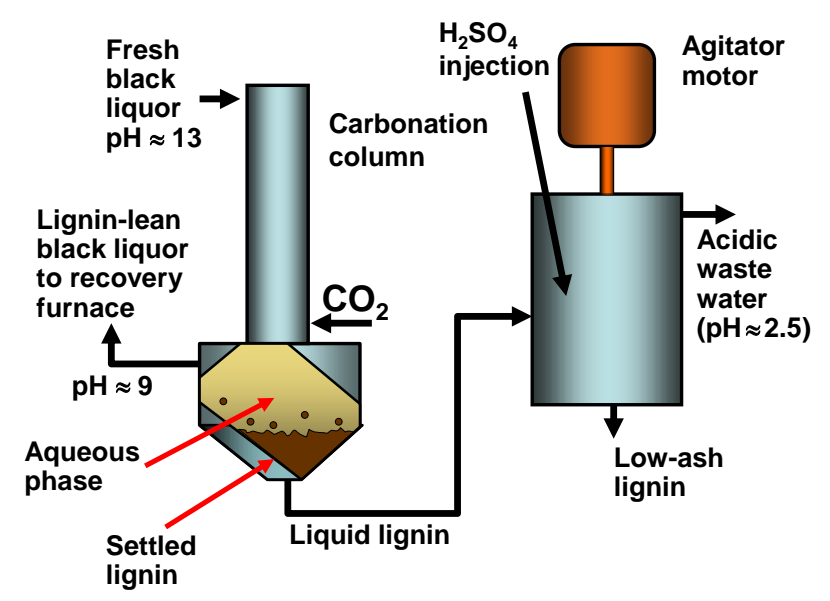

Fig. 8. Schematic diagram of a SLRP system with provisions for continuous operation

Velez and Thies (2016) found that the properties of lignin separated by the SLRP system were sensitive to the initial solids and ionic strength (salt content) of the black liquor. Higher black liquor solids and ionic strength gave higher yields of separated lignin with higher aromatic and aliphatic $-\mathrm{OH}$ content.

\section{Alternatives to the Recovery Boiler}

Eutectic freeze crystallization

As considered in a companion review article (Hubbe et al. 2018), if most of the lignin can be removed from black liquor, then one can consider the use of procedures other than conventional recovery boiler operations to recover and reactivate the inorganic components for use in alkaline pulping. This can be achieved, in principle, using eutectic 
freeze crystallization to sequentially separate out the sodium sulfate (as the decahydrate crystalline form) and the sodium carbonate (again as a hydrate crystal). Briefly stated, eutectic freeze crystallization involves simultaneous formation of ice crystals and specific inorganic compounds, such as sodium sulfate decahydrate. The ice floats and the salt crystals settle, facilitating their separation. The relatively pure salts either can be returned to a conventional recovery process or otherwise converted to sodium sulfide and sodium hydroxide (Hubbe et al. 2018). For example, an electrochemical approach can be used to reduce the sodium sulfate to sodium sulfide (Wartena et al. 2002). The same process simultaneously converts sodium carbonate to sodium hydroxide, thus potentially fulfilling the role of recausticization in a conventional kraft recovery system. Alternatively, one could apply electrochemical treatment of black liquor, using membrane systems to isolate the precipitated lignin from generated sodium hydroxide (Jin et al. 2013; Haddad et al. 2017a). In other work related to freezing, Feng and Tian (2009) demonstrated that oxidized black liquor can be concentrated, with a moderate energy expenditure, by selective freezing of ice. Although the key steps associated with eutectic freeze crystallization and other alternative approaches have been demonstrated in bench-scale tests, a great deal of developmental work will be required before implementation of a commercial-scale process.

\section{FINAL THOUGHTS}

The separation and recovery of lignin from spent pulping liquor has emerged as a commercially viable, large-scale industrial process, for which three versions are in current industrial production (Charleston mill, LignoBoost, and LignoForce) and a fourth has been demonstrated at the pilot plant scale (SLRP). The present review article has documented many experimental findings that can be helpful in understanding the chemical aspects of the lignin separation and other process steps. The technology is complex, with interacting process steps that have been optimized at the manufacturing and pilot-scale developmental sites. As documented in this article, some of the key factors governing the separation of lignin from black liquor are $\mathrm{pH}$, temperature, and the concentrations and types of metal ions.

Though there is potential to use lignin in a variety of higher-value applications, the complex chemical structure of lignin mixtures has so far discouraged most such developments. The low purity and variability of most kraft lignin, in comparison to, say, enzyme hydrolysis lignin (Rinaldi et al. 2016), has not been encouraging relative some high-end potential uses, such as for carbon fiber production from lignin.

In light of the demonstrated commercial viability of technology to separate lignin from black liquor, it is reasonable to expect increasing amounts of kraft lignin to be available in future years at relatively low cost. Such pricing and large-scale availability may spark innovative uses in the future. It is worth noting, however, that disruptive innovations often begin at a small scale (Christensen 2003; Dru 2015). For instance, there may be certain activated carbon products or phenol-formaldehyde resins (Feng et al. 2016) that can be produced directly from LignoBoost or LignoForce kraft lignin, perhaps without the need for washing steps. Alternatively, there may be specific acid-washing or fractionation steps that can be implemented to enable production of specialized carbon fibers or components for adhesives. Although the complicated, three-dimensionally bonded nature of lignin has tended to suppress its usage as a source for pure chemical 
compounds, the motivations of price and long-term availability - as well as uncertainties regarding the prices of petroleum-based materials - can be expected to prompt a lot of research interest in the coming years.

\section{ACKNOWLEGEMENTS}

The authors are greatly indebted to the following volunteers who provided corrections and suggestions for the submitted document: Dr. Hans Theliander, Chalmers University; Dr. Pedram Fatehi, Lakehead University; Dr. Hou-min Chang, North Carolina State University; Dr. Hasan Jameel, North Carolina State University; and Ms. Juliana Jardim, North Carolina State University.

\section{REFERENCES CITED}

Adams, T. N. (ed.) (1997). Kraft Recovery Boilers, TAPPI Press, Atlanta.

Alén, R. (2000a). "Structure and chemical composition of wood," in: Forest Products Chemistry, P. Stenius (ed.), Fapet, Helsinki, pp. 9-57.

Alén, R. (2000b). "Basic chemistry of wood delignification," in: Forest Products Chemistry, P. Stenius (ed.), Fapet, Helsinki, pp. 58-104.

Alén, R. (2011). "Principles of biorefining," in: Biorefining of Forest Resources, R. Alén (ed.), Paper Engineers' Association/Paperi ja Puu, Helsinki, pp. 55-114.

Alén, R. (2014). "Integrated possibilities of producing biofuels in chemical pulping, " in: Materials for Biofuels, A. J. Ragauskas (ed.), World Scientific Publishing, Singapore, pp. 317-338. DOI: 10.1142/9789814513289_0012

Alén, R. (2015). "Pulp mills and wood-based biorefineries," in: Industrial Biorefineries \& White Biotechnology, A. Pandey, R. Höfer, M. Taherzadeh, K. M., Nampoothiri, and C. Larroche (eds.), Elsevier, Amsterdam, pp. 91-126.

Alén, R. (2018). Carbohydrate Chemistry - Fundamentals and Applications, World Scientific Publishing, Singapore, 586 pp. DOI: 10.1142/10536

Alén, R., Lahtela, M., Niemelä, K., and Sjöström, E. (1985a). "Formation of hydroxy carboxylic acids from softwood polysaccharides during alkaline pulping," Holzforschung 39, 235-238. DOI: 10.1515/hfsg.1985.39.4.235

Alén, R., Moilanen, V.-P., and Sjöström, E. (1989). "Potential recovery of hydroxy acids from kraft pulping liquors," TAPPI 69(2), 76-78.

Alén, R., Patja, P., and Sjöström, E. (1979). "Carbon-dioxide precipitation of lignin from pine kraft black liquor," TAPPI 62(11), 108-110.

Alén, R., Sjöström, E., and Vaskikari, P. (1985b). "Carbon dioxide precipitation of lignin from alkaline pulping liquors," Cellulose Chem. Technol. 19(5), 537-541.

Alén, R., Sjöström, E., and Vaskikari, P. (1986). "Ultrafiltration studies on alkaline pulping liquors," Cellulose Chem. Technol. 20, 417-420.

Amriani, F., Barlianti, V., Muryanto, and Sari, A. A. (2015). "Activated carbon from lignin-based black liquor coagulated by polyaluminium chloride," in: International Symposium on Applied Chemistry 2015, S. Tursiloudi, M. Hanafi, and Y. Sudiyani (eds.), Book ser.: Procedia Chemistry, Vol. 16, pp. 134-140. DOI: 10.1016/j.proche.2015.12.041 
Arkell, A., Olsson, J., and Wallberg, O. (2014). "Process performance in lignin separation from softwood black liquor by membrane filtration," Chem. Eng. Res. Des. 92(9), 1792-1800. DOI: 10.1016/j.cherd.2013.12.018

Aro, T., and Fatehi, P. (2017). "Tall oil production from black liquor: Challenges and opportunities," Separ. Purif. Technol. 175, 469-480. DOI:

10.1016/j.seppur.2016.10.027

Arulanantham, M. E. L. N., and Shanthini, R. (1997). "Recovery of sodium hydroxide from Embilipitiya black liquor by electrolysis," IPPTA 9(3)1-8.

Axelsson, E., Olsson, M. R., and Berntsson, T. (2006). "Increased capacity in kraft pulp mills: Lignin separation and reduced steam demand compared with recovery boiler upgrade," Nordic Pulp Paper Res. J. 21(4), 485-492. DOI: 10.3183/NPPRJ-2006-2104-p485-492

Back, E. L., and Allen, L. H., (eds.) (2000). Pitch Control, Wood Resin and Deresination, TAPPI Press, Atlanta, GA, 392 pp.

Back, S. (2018). "The world's first lignin plant for biofuels," Paper Advance (blog), https://www.paperadvance.com/blogs/2015-09-21-18-40-27/9709-the-worlds-firstlignin-plant-for-biofuels-.html

Bajpai, P. (2017). Pulp and Paper Industry Chemical Recovery, Elsevier, Amsterdam.

Ball, F. J., and Vardell, W. C. (1962). "Continuous acidulation and coagulation of lignin in black liquor," U.S. Patent No. 3,048,576.

Bi, S. P., Wang, C. Y., Cao, Q., and Zhang, C. H. (2004). "Studies on the mechanism of hydrolysis and polymerization of aluminum salts in aqueous solution: Correlations between the 'Core-links' model and 'cage-like' Keggin- $\mathrm{Al}_{13}$ model," Coordination Chem. Rev. 248, 441-455. DOI: 10.1016/j.ccr.2003.11.001

Biermann, C. J. (1996). Handbook of Pulping and Papermaking, $2^{\text {nd }}$ Ed., Academic Press, San Diego, CA.

Blanco, A., Negro, C., Tijero, J., Jong, M. C. P. D., and Schmal, D. (1996).

"Electrochemical treatment of black liquor from a straw pulping," Sep. Sci. Technol. 31(19), 2705-2712. DOI: 10.1080/01496399608000821

Bottero, J.-Y., and Fiessinger, F. (1989). "Aluminum chemistry and aqueous solution," Nordic Pulp Paper Res. J. 4(2), 81-89. DOI: 10.3183/NPPRJ-1989-04-02-p081-089

Bozell, J., Holladay, J., Johnson, D., and White, J. (2007). Top Value Added Chemicals from Biomass -Volume II: Results of Screening for Potential Candidates from Biorefinery Lignin, U.S. Department of Energy, Oak Ridge, TN, 79 pp.

Calvo-Flores, F. G., Dobado, J. A., Isac-Garcia, J., and Martin-Martinez, F. J. (2015). Lignin and Lignans as Renewable Raw Materials: Chemistry, Technology, and Applications, Wiley, Chichester, UK. DOI: 10.1002/9781118682784

Christensen, C. M. (2003). The Innovators Solution: Creating and Sustaining Successful Growth, Harvard Business School Press, Boston, MA.

Clayton, D., Easty, D., Einspahr, D., and Lonsky, W. (1989). “Kraft liquors,” in: Pulp and Paper Manufacture, Vol 5, Alkaline Pulping, The joint Committee of the Paper Industry, TAPPI and CPPA, Atlanta, GA and Montreal, pp. 15-22.

Cloutier, J. N., Azarniouch, M. K., and Callender, D. (1993). "Electrolysis of weak black liquor. Part I: Laboratory study,” J. Pulp Paper Sci. 19(6), 244-248.

Cloutier, J. N., Azarniouch, M. K., and Callender, D. (1994). "Electrolysis of weak black liquor. Part III: Continuous operation test and system design considerations," Pulp Paper Canada 95(5), 210-241. 
Cloutier, J. N., Azarniouch, M. K., and Callender, D. (1995). "Electrolysis of weak black liquor. Part II: Effect of process parameters on the energy efficiency of the electrolytic cell," J. Appl. Electrochem. 25(5), 472-478. DOI: 10.1007/BF00260690

Coheen, D. W. (1981). "Chemicals from lignin," in Organic Chemicals from Biomass, I. S. Goldstein (ed.), CRC Press, Boca Raton, FL, pp. 143-161.

Costa, C. A. E., Pinto, P. C. R., and Rodrigues, A. E. (2018). "Lignin fractionation from E. Globulus kraft liquor by ultrafiltration in a three stage membrane sequence," Separ. Purif. Technol. 192, 140-151. DOI: 10.1016/j.seppur.2017.09.066

Culbertson, C., Treasure, T., Venditti, R., Jameel, H., and Gonzalez, R. (2016). "Life cycle assessment of lignin extraction in a softwood kraft pulp mill," Nordic Pulp Paper Res. J. 31(1), 30-U247. DOI: 10.3183/NPPRJ-2016-31-01-p030-040

Danielsson, S. (2014). "Sorption and desorption of black liquor xylan onto cellulose fibers - A new separation technique," Cellulose Chem. Technol. 48(9-10), 819-823.

De, S., and Bhattacharya, P. K. (1996). "Recovery of water and inorganic chemicals from kraft black liquor using membrane separation processes," TAPPI J. 79(1), 103-111.

Derjaguin, B. V., and Landau, L. D. (1941). "Theory of the stability of strongly charged lyophobic sols and the adhesion of strongly charged particles in solution of electrolytes," Acta Physicochim. URSS 14, 633-662.

Dhingra, D. R., Bhatnagar, M. S., and Nigam, P. C. (1952). "Lignin recovery from soda black liquor," Indian Pulp Paper 7(6), 311-315.

Dominguez-Robles, J., Espinosa, E., Savy, D., Rosal, A., and Rodriguez, A. (2016). "Biorefinery process combining Specel $(\mathrm{R})$ process and selective lignin precipitation using mineral acids," BioResources 11(3), 7061-7077. DOI: 10.15376/biores.11.3.7061-7077

Dong, D., Fricke, A. L., Moudgil, B. M., and Johnson, H. (1996). "Electrokinetic study of kraft lignin," TAPPI J. 79(7), 191-197.

dos Santos, P. S. B., Erdocia, X., Gatto, D. A., and Labidi, J. (2014). "Characterisation of kraft lignin separated by gradient acid precipitation," Indust. Crops Prod. 55, 149154. DOI: 10.1016/j.indcrop.2014.01.023

Dru, J.-M. (2015). The Ways to New: 15 Paths to Disruptive Innovation, John Wiley \& Sons, Hoboken, NJ. DOI: 10.1002/9781119214731

Durruty, J., Mattsson, T., and Theliander, H. (2017a). "Local filtration properties of kraft lignin: The influence of residual xylan," Separ. Purif. Technol. 179, 455-466. DOI: 10.1016/j.seppur.2017.01.068

Durruty, J., Sewring, T., Schneider, H., Schneider, L., Mattsson, T., and Theliander, H. (2017b). "Filtration properties of kraft lignin: The influence of xylan and precipitation conditions," Nordic Pulp Paper Res. J. 32(4), 508-526. DOI: 10.3183/NPPRJ-201732-04-p508-526

Dutka, A. P., Basker, V. R., Crisalle, O. D., Fricke, A. L., and Kalotay, P. (2004). "Evaluation of a capillary-coriolis instrument for on-line viscosity and density measurements of kraft black liquor," TAPPI J. 3(3), 17-24.

Edzwald, J. K. (2010). "Dissolved air flotation and me," Water Res. 44(7), 2077-2106. DOI: $10.1016 /$ j.watres.2009.12.040

Empie, H. J. (2009). Fundamentals of the Kraft Recovery Process, TAPPI Press, Atlanta, GA.

Exall, K. N., and van Loon, G. W. (2003). "Effects of raw water conditions on solutionstate aluminum speciation during coagulant dilution," Water Res. 37(14), 3341-3350. DOI: 10.1016/S0043-1354(03)00229-X 
Fane, A. G., and Fell, C. J. D. (1987). “A review of fouling and fouling control in ultrafiltration," Desalination 62, 117-136. DOI: 10.1016/0011-9164(87)87013-3

FAOSTAT (2014). Food and Agriculture Organization of the United Nations. URL: http://faostat.fao.org

Fardim, P. (ed.) (2011). Chemical Pulping, Part 1, Fibre Chemistry and Technology, Paper Engineers Assoc./Paperi ja Puu Oy, $2^{\text {nd }}$ Ed., Helsinki, 748 pp.

Fatehi, P., Gao, W. J., Sun, Y. H., and Dashtban, M. (2016). "Acidification of prehydrolysis liquor and spent liquor of neutral sulfite semichemical pulping process," Bioresour. Technol. 218, 518-525. DOI: 10.1016/j.biortech.2016.06.138

Feng, M. W., He, G., Zhang, Y., Wang, X.-M., Kouisni, L., and Paleologou, M. (2016). "High-residual content (HRC) kraft/soda lignin as an ingredient in wood adhesives," U.S. Patent No. 20160304757, October 20, 2016.

Feng, X. Z., and Tian, Z. Y. (2009). "A new technology for treating pulp waste with plasma," Plasma Sci. Technol. 11(5), 609-612. DOI: 10.1088/1009-0630/11/5/18

Flory, P. J. (1953). Principles of Polymer Chemistry, Cornel Univ. Press, Ithaca, NY.

Frederick, W. J. (1997). "Black liquor properties," in: Kraft Recovery Boilers, T. N. Adams (ed.), TAPPI Press, Atlanta, GA, pp. 59-99.

Fritz, C., Salas, C., Jameel, H., and Rojas, O. U. (2017). 'Self-association and aggregation of kraft lignins via electrolyte and nonionic surfactant regulation: Stabilization of lignin particles and effects on filtration," Nordic Pulp Paper Res. J. 32(4), 572-585. DOI 10.3183/NPPRJ-2017-32-04-p572-585

Garcia, A., Toledano, A., Serrano, L., Egues, I., Gonzalez, M., Marin, F., and Labidi, J. (2009). "Characterization of lignins obtained by selective precipitation," Separ. Purif. Technol. 68(2), 193-198. DOI: 10.1016/j.seppur.2009.05.001

Garg, A., Mishra, I. M., and Chand, S. (2010). "Effectiveness of coagulation and acid precipitation processes for the pre-treatment of diluted black liquor," J. Hazard. Mater. 180, 158-164. DOI: 10.1016/j.jhazmat.2010.04.008

Gellerstedt, G., Tomani, P., Axegård, P., and Backlund, B. (2013). "Lignin recovery and lignin-based products," in: Integrated Forest Biorefineries - Challenges and Opportunities, C. Lew (ed.), Royal Soc. Chem., Cambridge, pp. 180-210.

Ghatak, H. R. (2009a). "Reduction of organic pollutants with recovery of value-added products from soda black liquor of agricultural residues by electrolysis," TAPPI J. $8(7), 4-10$.

Ghatak, H. R. (2009b). "Economic potential of black liquor electrolysis as a treatment option for small agro-based mills," TAPPI J. 8(11), 4-11.

Ghatak, H. R., Kundu, P. P., and Kumar, S. (2010). "Thermochemical comparison of lignin separated by electrolysis and acid precipitation from soda black liquor of agricultural residues," Thermochim. Acta 502(1-2), 85-89. DOI: 10.1016/j.tca.2010.02.012

Gierer, J. (1970). "The reactions of lignin during pulping - A description and comparison of conventional pulping processes," Svensk Papperstidn. 73(18), 571-595.

Gierer, J. (1980). “Chemical aspects of kraft pulping," Wood Sci. Technol. 14, 241-266. DOI: $10.1007 / \mathrm{BF} 00383453$

Gierer, J. (1982). "The chemistry of delignification," Holzforschung 36(1), 43-51. DOI: 10.1515/hfsg. 1982.36.1.43

Gierer, J. (1985). "Chemistry of delignification. Part 1: General concept and reactions during pulping," Wood Sci. Technol. 19, 289-312. 
Gilarranz, M. A., Rodriguez, F., Oliet, M., and Revenga, J. A. (1998). “Acid precipitation and purification of wheat straw lignin," Separ. Sci. Technol. 33(9), 1359-1377. DOI: 10.1080/01496399808544988

Giummarella, N., Lindgren, C., Lindstrom, M. E., and Henriksson, G. (2016). “Lignin prepared by ultrafiltration of black liquor: Investigation of solubility, viscosity, and ash content," BioResources 11(2), 3494-3510. DOI: 10.15376/biores.11.2.3494-3510

Glasser, W. G., Barnett, C. A., and Sano, Y. (1983). "Classification of lignins with different genetic and industrial origins," J. Appl. Polym. Sci. 37, 441-460.

Goring, D. A. I. (1971). "Polymer properties of lignin and lignin derivatives," in: Lignins. Occurrence, Formation, Structure and Reactions, K. V. Sarkanen and C. H. Ludwig (eds.), Wiley-Interscience, New York, Ch. 17, pp. 695-768.

Grace, T. M. (1992). "Chemical recovery process chemistry," in: Chemical Recovery in the Alkaline Pulping Processes, R. P. Green and G. Hough (eds.), $3^{\text {rd }}$ Ed., TAPPI Press, Atlanta, GA, Ch. 5, pp. 57-78.

Grace, T. M., Malcolm, E. W., and Kocurek, M. J. (eds.) (1989). Pulp and Paper Manufacture, Vol. 5, Alkaline Pulping, The Joint Committee of the Paper Industry, TAPPI and CPPA, Atlanta, GA and Montreal, $637 \mathrm{pp}$.

Gray, K., Crosby, H. L., and Steinberg, J. C. (1953). "Recovery of chemicals in wood pulp preparation," U.S. Patent No. 2,772,965.

Gustafsson, J., Alén, R., Engström, J., Korpinen, R., Kuusisto, P., Leavitt, A., Olsson, K., Piira, J., Samuelsson, A., and Sundquist, J. (2008). "Pulping," in: Chemical Pulping. Part 1, Fiber Chemistry and Technology, $2^{\text {nd }}$ Ed., P. Fardim (ed.), Ch. 2, pp. 187-381. Book series: Papermaking Science and Technology, Paper Engineers' Association/Paperi ja Puu, $2^{\text {nd }}$ Ed., Helsinki.

Haddad, M., Labrecque, R., Bazinet, L., Savadogo, O., and Paris, J. (2016). "Effect of process variables on the performance of electrochemical acidification of kraft black liquor by electrodialysis with bipolar membrane," Chem. Eng. J. 304, 977-985. DOI: 10.1016/j.cej.2016.07.030

Haddad, M., Bazinet, L., Savadogo, O., and Paris, J. (2017a). "A feasibility study of a novel electro-membrane based process to acidify kraft black liquor and extract lignin," Process Saf. Environ. 106, 68-75. DOI: 10.1016/j.psep.2016.10.003

Haddad, M., Bazinet, L., Savadogo, O., and Paris, J. (2017b). "Electrochemical acidification of kraft black liquor: Impacts of pulsed electric field application on bipolar membrane colloidal fouling and process intensification," J. Membrane Sci. 524, 482-492. DOI: 10.1016/j.memsci.2016.10.043

Haddad, M., Mikhaylin, S., Bazinet, L., Savadogo, O., and Paris, J. (2017c). "Electrochemical acidification of kraft black liquor: Effect of fouling and chemical cleaning on ion exchange membrane integrity," ACS Sust. Chem. Eng. 5(1), 168-178. DOI: 10.1021/acssuschemeng.6b01179

Hansen, C. M. (2007). Hansen Solubility Parameters: A User's Handbook, $2^{\text {nd }}$ Ed., CRC Press, Boca Raton, FL, USA. DOI: 10.1201/9781420006834

Hardy, W. B. (1899). "A preliminary investigation of the conditions which determine the stability of irreversible hydrosols," Proc. Royal Soc. London 66, 110-125. DOI: 10.1098/rspl.1899.0081

Helander, M., Mattsson, T., Theliander, H., and Lindstrom, M. E. (2015). "Parameters affecting the cross-flow filtration of dissolved LignoBoost kraft lignin," J. Wood Chem. Technol. 36(1), 1-8. DOI: 10.1080/02773813.2015.1025284 
Helander, M., Theliander, H., Lawoko, M., Henriksson, G., Zhang, L. M., and Lindstrom, M. E. (2013). "Fractionation of technical lignin: Molecular mass and pH effects," BioResources 8(2), 2270-2282. DOI: 10.15376/biores.8.2.2270-2282

Hiemenz, P. C., and Rajagopalan, R. (1997). Principles of Colloid and Surface Science, $3^{\text {rd }}$ Ed., Dekker, New York, NY. DOI: 10.1201/9781315274287

Hill, M., and Fricke, A. L. (1984). "Ultrafiltration studies on a kraft black liquor," TAPPI 67(6), 100-103.

Holmbom, B. (2011). "Extraction and utilization of non-structural wood and bark components," in: Biorefining of Forest Resources, R. Alén (ed.), Paper Engineers' Association/Paperi ja Puu, Helsinki, pp. 176-224.

Holmqvist, A., Wallberg, O., and Jönsson, A. S. (2005). "Ultrafiltration of kraft black liquor from two Swedish pulp mills," Chem. Eng. Res. Des. 83(A8), 994-999. DOI: 10.1205/cherd.04204

Hon, D. N.-S., and Shiraishi, N. (eds.) (2001). Wood and Cellulosic Chemistry, Marcel Dekker, New York, NY, $2^{\text {nd }} E d ., 914$ pp.

Howell, J. F., and Thring, R. W. (2000). "Hardwood lignin recovery using generator waste acid. Statistical analysis and simulation," Indust. Eng. Chem. Res. 39(7), 25342540. DOI: 10.1021/ie990190q

Hu, Z. J., Du. X. Y., Liu, J., Chang, H.-m., and Jameel, H. (2016). "Structural characterization of pine kraft lignin: BioChoice lignin vs. Indulin AT," J. Wood Chem. Technol. 36(6), 432-446. DOI: 10.1080/02773813.2016.1214732

Huang, H. J., Ramaswamy, S., Al-Dajani, W. W., and Tschirner, U. (2010). "Process modeling and analysis of pulp mill-based integrated biorefinery with hemicellulose pre-extraction for ethanol production: A comparative study," Bioresour. Technol. 101(2), 624-631. DOI: 10.1016/j.biortech.2009.07.092

Hubbe, M. A., Bechelini, E. M. A., Lewis, A. E., Peters, E. M., Gan, W. X., Nong, G. Z., Mandal, S., and Shi, S. Q. (2018). "Recovery of inorganic compounds from spent pulping liquor by eutectic freeze crystallization and supporting unit operations: A review," BioResources 13(4), 9180-9219. DOI: 10.15376/biores.13.4.Hubbe

Hubbe, M. A., Chen, H., and Heitmann, J. A. (2009). "Permeability reduction phenomena in packed beds, fiber mats, and wet webs of paper exposed to flow of liquids and suspensions: A review," BioResources 4(1), 405-451. DOI: 10.15376/biores.4.1.405451

Hubbe, M. A., Gardner, D. J., and Shen, W. (2015). "Contact angles and wettability of cellulosic surfaces: A review of proposed mechanisms and test strategies," BioResources 10(4), 8657-8749.DOI: 10.15376/biores.10.4.Hubbe_Gardner_Shen

Hubbe, M. A., Metts, J. R., Hermosilla, D., Blanco, M. A., Yerushalmi, L., Haghighat, F., Lindholm-Lehto, P., Khodaparast, Z., Kamali, M., and Elliott, A. (2016).

"Wastewater treatment and reclamation: A review of pulp and paper industry practices and opportunities," BioResources 11(3), 7953-8091. DOI: 10.15376/biores.11.3.Hubbe

Hubbe, M. A., and Rojas, O. J. (2008). "Colloidal stability and aggregation of lignocellulosic materials in aqueous suspension: A review," BioResources 3(4), 14191491. DOI: 10.15376/biores.3.4.1419-1491

Humpert, D., Ebrahimi, M., and Czermak, P. (2016). "Membrane technology for the recovery of lignin: A review," Membranes 6(3), article no. 42. DOI: 10.3390/membranes6030042 
Jamaly, S., Giwa, A., and Hasan, S. W. (2015). "Recent improvements in oily wastewater treatment: Progress, challenges, and future opportunities," J. Environ. Sci. 37, 15-30. DOI: 10.1016/j.jes.2015.04.011

Jiang, X., Liu, J., Du, X. Y., Hu, Z. J., Chang, H.-m., and Jameel, H. (2018). "Phenolation to improve lignin reactivity toward thermosets application," ACS Sust. Chem. Eng. 6, 5504-5512. DOI: 10.1021/acssuschemeng.8b00369

Jiang, X., Savthri, D., Du, X., Pawar, S., Jameel, H., Chang, H.-m., and Zhou, X. F. (2017). "Fractionation and characterization of kraft lignin by sequential precipitation with various organic solvents," ACS Sust. Chem. Eng. 5(1), 835-842. DOI: 10.1021/acssuschemeng.6b02174

Jin, W., Tolba, R., Wen, J. L., Li, K. C., and Chen, A.C. (2013). "Efficient extraction of lignin from black liquor via a novel membrane-assisted electrochemical approach," Electrochim. Acta 107, 611-618. DOI: 10.1016/j.electacta.2013.06.031

Johansson, A. (1982). 'By-product recovery and valorization in the kraft industry - A review of current trends in the recovery and use of turpentine and tall oil derivatives," Biomass 2(2), 103-113. DOI: 10.1016/0144-4565(82)90020-8

Jönsson, A. S., Nordin, A. K., and Wallberg, O. (2008). "Concentration and purification of lignin in hardwood kraft pulping liquor by ultrafiltration and nanofiltration," Chem. Eng. Res. Des. 86(11A), 1271-1280. DOI: 10.1016/j.cherd.2008.06.003

Junker, E. (1941). "Zur Kenntnis der Kolloidchemischen Eigneschaften des Humus Beigtrag zur Dispersitätschemie des Lignins," Kolloid Zeitschr. 95, 213-250. DOI: 10.1007/BF01521463

Kannangara, M., Marinova, M., Fradette, L., and Paris, J. (2012). "Lignin recovery by aid precipitation in a kraft mill: An energy perspective," JFor - J. Sci. Techno. For. Prod. Proc. 2(4), 28-32.

Kannangara, M., Marinova, M., Fradette, L., and Paris, J. (2016). "Effect of mixing hydrodynamics on the particle and filtration properties of precipitated lignin," Chem. Eng. Res. Des. 105, 94-106. DOI: 10.1016/j.cherd.2015.11.003

Kaur, B., and Chakraborty, D. (2013). "Biotechnological and molecular approaches for vanillin production: A review," Appl. Biochem. Biotechnol. 169(4), 1353-1372. DOI: 10.1007/s12010-012-0066-1

Keilen Jr., J. J., Ball, F. J., and Gressang, R. W. (1950). "Method of coagulating colloidal lignates in aqueous dispersions," U.S. Patent No. 2,623,040.

Keilen, J. J., Frank, J. B., and Gressang, R. W. (1952). "Method of coagulating lignates in aqueous dispersions," U.S. Patent No. 2,623,040.

Kevlich, N. S., Shofner, M. L., and Nair, S. (2017). "Membranes for kraft black liquor concentration and chemical recovery: Current progress, challenges, and opportunities," Separ. Sci. Technol. 52(6), 1070-1094. DOI: 10.1080/01496395.2017.1279180

Keyoumu, A., Sjodahl, R., Henriksson, G., Ek, M., Gellerstedt, G., and Lindstrom, M. E. (2004). "Continuous nano- and ultra-filtration of kraft pulping black liquor with ceramic filters - A method for lowering the load on the recovery boiler while generating valuable side-products," Indust. Crops Prod. 20(2), 143-150. DOI: 10.1016/j.indcrop.2004.04.017

Khulbe, K. C., Feng, C. Y., and Matsuura, T. (2008). Synthetic Polymer Membranes. Characterization by Atomic Force Microscopy, Springer, Berlin, 197 pp. 
Kihlman, J. (2016). "The sequential liquid-lignin recovery and purification process: Analysis of integration aspects for a kraft pulp mill," Nordic Pulp Paper Res. J. 31(4), 573-582. DOI: 10.3183/NPPRJ-2016-31-04-p573-582

Kiiskilä, E., and Virkola, N.-E. (1987). "Method of decreasing black liquor viscosity," PCT Int. Appl. WO 87/03315.

Kouisni, L., Gagne, A., Maki, K., Holt-Hindle, P., and Paleologou, M. (2016). "LignoForce system for the recovery of lignin from black liquor: Feedstock options, odor profile, and product characterization," ACS Sust. Chem. Eng. 4(10), 5152-5159. DOI: 10.1021/acssuschemeng.6b00907

Kouisni, L., Holt-Hindle, P., Maki, K., and Paleologou, M. (2012). "The Lignoforce system (TM): A new process for the production of high-quality lignin from black liquor," J-FOR-J. Sci. Technol. For. Prod. Proc. 2(4), 6-10.

Kouisni, L., Holt-Hindle, P., Maki, K., and Paleologou, M. (2014). "The Lignoforce system (TM): A new process for the production of high-quality lignin from black liquor," Pulp Paper Canada 115(1), 18-22.

Kouisni, L., and Paleologou, M. (2014a). "Method for separating lignin from black liquor," U.S. Patent No. 8,771, 464.

Kouisni, L., and Paleologou, M. (2014b). "The Lignoforce system - A new process for the production of kraft lignin for high-value products," in: Professional Development Courses - Designing the Forest Biorefinery, Stockholm, Sweden, pp. 1-31.

Kouisni, L., Fang, Y. L., Paleologou, M., Ahvazi, B., Hawari, J., Zhang Y. L., and Wang, X.-M. (2011). "Kraft lignin recovery and its use in the preparation of lignin-based phenol formaldehyde resins for plywood," Cellulose Chem. Technol. 45(7-8), 515520.

Kumar, H. (2016). Novel Products on the Recovery of By-products from Alkaline Pulping, Ph.D. thesis, Univ. Jyväskylä, Finland.

Kumar, H., and Alén, R. (2014). "Partial recovery of aliphatic carboxylic acids and sodium hydroxide from hardwood black liquor by electrodialysis," Ind. Eng. Chem. Res. 53, 9464-9470. DOI: 10.1021/ie5006004

Kumar, H., Alén, R., and Sahoo, G. (2016). "Characterization of hardwood soda-AQ lignins precipitated from black liquor through selective acidification," BioResources 11(4), 9869-9879. DOI: 10.15376/biores.11.4.9869-9879

Lake, M. A., and Blackburn, J. C. (2011). "Process for recovering lignin," U.S. Patent No. 2011/0294991.

Lake, M. A., and Blackburn, J. C. (2014). "SLRP (TM) - An innovative lignin-recovery technology," Cellulose Chem. Technol. 48(9-10), 799-804.

Lake, M. A., and Blackburn, J. C. (2016). "Process for recovering lignin,” U.S. Patent No. 9,260,464.

Lake, M. A., Blackburn, J. C., and Stevens, D. (2015). "SLRP mass balance interface streams," http://ww.liquidlignin.com

Lawoko, M., Henriksson, G., and Gellerstedt, G. (2005). "Structural differences between the lignin-carbohydrate complexes present in wood and in chemical pulps," Biomacromol. 6(6), 3467-3473. DOI: 10.1021/bm058014q

Lawoko, M., Henriksson, G., and Gellerstedt, G. (2006). "Characterisation of lignincarbohydrate complexes (LCCs) of spruce wood (Picea abies L.) isolated with two methods," Holzforschung 60(2), 156-161. DOI: 10.1515/HF.2006.025 
Lee, S. Y., Hubbe, M. A., and Saka, H. (2006). "Prospects for biodiesel as a byproduct of wood pulping - A review," BioResources 1(1), 150-171. DOI:

10.15376/biores.1.1.116-149

Lehto, J., Pakkanen, H., and Alén, R. (2015). "Molecular mass distribution of sulfur-free lignin from alkaline pulping preceded by hot-water-extraction," Appita J. 68(2), 149157.

Leskinen, T., Smyth, M., Xiao, Y., Lintinen, K., Mattinen, M.-L., Kostiainen, M. A., Oinas, P., and Österberg, M. (2017). "Scaling up production of colloidal lignin particles,” Nordic Pulp Paper Res. J. 32(4), 586-596. DOI: 10.3183/NPPRJ-2017-3204-p586-596

Lin, S. Y. (1992). "Ultrafiltration," in: Method in Lignin Chemistry, Y. L. Stephen, and C. D. Dence (eds.), Springer, Heidelberg, pp. 518-523. DOI: 10.1007/978-3-64274065-7_37

Lindström, T. (1979). "Colloidal behavior of kraft lignin.1. Association and gelation of kraft lignin in aqueous-solutions," Colloid Polym. Sci. 257(3), 277-285. DOI: 10.1007/BF01382370

Lindström, T. (1980). "The colloidal behavior of kraft lignin. 2. Coagulation of kraft lignin sols in the presence of simple and complex metal-ions," Colloid Polym. Sci. 258(2), 168-173. DOI: 10.1007/BF01498276

Lisboa, S. A., Evtuguin, D. V., Neto, C. P., and Goodfellow, B. J. (2005). "Isolation and structural characterization of polysaccharides dissolved in Eucalyptus globulus kraft black liquors," Carbohydr. Polym. 60(1), 77-85. DOI: 10.1016/j.carbpol.2004.11.024

Liu, Z., and Luo, X. G. (2010). "Fractional isolation and purification of lignin from pulping black liquor," in $20104^{\text {th }}$ International Conference on Bioinformatics and Biomedical Engineering (ICBBE 2010), Chengdu, China.

Löfstedt, J., Dahlstrand, C., Orebom, A., Meuzelaar, G., Sawadjoon, S., Galkin, M. V., Agback, P., Wimby, M., Corresa, E., Mathieu, Y., Sauvanaud, L., Eriksson, S., Corma, A., and Samec, J. S. M. (2016). "Green diesel from kraft lignin in three steps," ChemSusChem 9(12), 1392-1396. DOI: 10.1002/cssc.201600172

Lora, J. (2008). "Industrial commercial lignins: Sources, properties and applications," in: Monomers, Polymers and Composites from Renewable Resources, M. N. Belgacem and A. Gandini (eds.), pp. 225-241. DOI: 10.1016/B978-0-08-045316-3.00010-7

Louhelainen, J. (2003). Changes in the Chemical Composition and Physical Properties of Wood and Nonwood Black Liquors during Heating, Ph.D. thesis, Univ. Jyväskylä, Finland.

Loutfi, H., Blakwell, B., and Uloth, V. (1991). "Lignin recovery from kraft black liquor: Preliminary process design," Tappi J. 74(1), 203-210.

Lund (2016). https://www.chemeng.lth.se/ket050/Finalreport2016/SunCarbon.pdf

Macfarlane, A. L., Prestidge, R., Farid, M. M., and Chen, J. J. J. (2009). "Dissolved air flotation: A novel approach to recovery of organosolv lignin," Chem. Eng. J. 148(1), 15-19. DOI: 10.1016/j.cej.2008.07.036

Mandavgane, S. A., and Subramanian, D. (2006). "Settling and filtration characteristics of carbonated black liquor from agro based paper mill," J. Sci. Indust. Res. 65(2), 169-173.

Manttari, M., Lahti, J., Hatakka, H., Louhi-Kultanen, M., and Kallioinen, M. (2015). "Separation phenomena in UF and NF in the recovery of organic acids from kraft black liquor,” J. Membrane Sci. 490, 84-91. DOI: 10.1016/j.memsci.2015.04.048 
Marcus, Y. (1993). "The properties of organic liquids that are relevant to their use as solvating solvents," Chem. Soc. Rev. 22(6), 409-416. DOI: 10.1039/cs9932200409

Marton, J. (1971). "Reactions in alkaline pulping," in: Lignins. Occurrence, Formation, Structure and Reactions, K. V. Sarkanen and C. H. Ludwig (eds.), WileyInterscience, New York, NY, Ch. 16, pp. 639-694.

Mattsson, T., Lewis, W. J. T., Chew, Y. M. J., and Bird, M. R. (2015). "In situ investigation of soft cake fouling layers using fluid dynamic gauging," Food Bioprod. Proc. 93, 205-210. DOI: 10.1016/j.fbp.2014.09.003

McGinnis, T., Svarz, J., and Gabel, R. (1998). “Additives for improving the separation of crude tall oil soap from black liquor and analytical methods for measurement of their performance," TAPPI Pulping Conf., Montreal, Oct. 25-29, 1998, TAPPI Press, Atlanta, GA, pp. 191-934.

Merewether, J. W. T. (1962a). "The precipitation of lignin from eucalyptus kraft black liquors," TAPPI 45(2), 159-163.

Merewether, J. W. T. (1962b). "Lignin XV. The coagulation of lignin salt from acidified kraft black liquor," Holzforschung 16(1), 26-29. DOI: 10.1515/hfsg.1962.16.1.26

Mesfun, S., Lundgren, J., Grip, C. E., Toffolo, A., Nilsson, R. L. K., and Rova, U. (2014). "Black liquor fractionation for biofuels production - A techno-economic assessment," Bioresour. Technol. 166, 508-517. DOI: 10.1016/j.biortech.2014.05.062

Milanova, E., and Dorris, G. M. (1990). "Effects of residual alkali content on the viscosity of kraft black liquors," J. Pulp Pap. Sci. 16(3), 94-101.

Mishra, A. K., and Bhattacharya, P. K. (1984). "Alkaline black liquor treatment by batch electrodialysis," Can. J. Chem. Eng. 62, 723-727. DOI: 10.1002/cjce.5450620520

Mishra, A. K., and Bhattacharya, P. K. (1987). "Alkaline black liquor treatment by continuous electrodialysis,” J. Membr. Sci. 33, 83-95. DOI: 10.1016/S03767388(00)80053-8

Monhemius, A. J. (1977). "Precipitation diagrams for metal-hydroxides, sulfides, arsenates and phosphates," Trans. Inst. Mining Metal. Sec. C-Min. Proc. Extrac. Metal. 86(Dec.), C202-C206.

Moosavifar, A. (2006). "Viscosity and boiling point elevation of black liquor. Consequences when lignin is extracted from the black liquor," Nordic Pulp Paper Res. J. 21(2), 180-187. DOI: 10.3183/NPPRJ-2006-21-02-p180-187

Moosavifar, A. (2008). "Lignin extraction from black liquor - Properties of the liquors and sulphur content in the lignin," Chalmers University of Technology, Gothenburg, Sweden.

Moreva, Y. L., Alekseeva, N. S., and Chernoberezhskii, Y. M. (2011). "Influence of $\mathrm{NaOH}, \mathrm{HCl}, \mathrm{NaCl}$, and $\mathrm{CaCl}_{2}$ electrolytes on aggregation stability of aqueous kraft lignin dispersion according to data of filtration through track membranes," Colloid J. 73(3), 363-367. DOI: 10.1134/S1061933X11030082

Moreva, Y. L., and Chernoberezhskii, Y. M. (2011). "Influence of $\mathrm{AlCl}_{3}$ on aggregation stability of aqueous dispersions of kraft lignin according to filtration through track membranes," Colloid J. 73(6), 822-824. DOI: 10.1134/S1061933X11050085

Moshkelani, M., Marinova, M., Perrier, M., and Paris, J. (2013). "The forest biorefinery and its implementation in the pulp and paper industry: Energy overview," Appl. Therm. Eng. 50(2), 1427-1436. DOI: 10.1016/j.applthermaleng.2011.12.038

Mota, M. I. F., Pinto, P. C. R., Loureiro, J. M., and Rodrigues, A. E. (2016). "Recovery of vanillin and syringaldehyde from lignin oxidation: A review of separation and 
purification processes," Separ. Purif. Revs. 45(3), 227-259. DOI:

$10.1080 / 15422119.2015 .1070178$

Murray, F. E., and Prakash, C. B. (1976). "Studies on the oxidation of organic sulphides in kraft black liquor," TAPPI J. 77(8), 47-52; T144-T148.

Mussatto, S. I., Fernandes, M., and Roberto, I. C. (2007). "Lignin recovery from brewer's spent grain black liquor," Carbohydr. Polym. 70(2), 218-223. DOI:

10.1016/j.carbpol.2007.03.02

Nagy, M., Kosa, M., Theliander, H., and Ragauskas, A. J. (2010). "Characterization of $\mathrm{CO}_{2}$ precipitated kraft lignin to promote its utilization," Green Chem. 12(1), 31-34. DOI: $10.1039 / \mathrm{b} 913602 \mathrm{a}$

Namane, M., Garcia-Mateos, F. J., Sithole, B., Ramjugernath, D., Rodriguez-Mirasol, J., and Cordero, T. (2016). "Characteristics of lignin precipitated with organic acids as a source for valorisation of carbon products," Cellulose Chem. Technol. 50(3-4), 355360.

Namane, M., Sithole, B. B., and Ramjugernath, D. (2015). "Centrifugal washing and recovery as an improved method for obtaining lignin precipitated from South African kraft mill black liquor," J. Sci. Indust. Res. 74(10), 571-576.

Negro, C., Blanco, A., Tijero, J., Villarin, S., Erkel, J. V., and Jong, M. C. P. D. (2005). "Electrochemical treatment of straw weak black liquor from a Kraft pulping plant," Cellul. Chem. Technol. 39(1-2), 129-136.

Neto, C. P., Belino, E., Evtuguin, D., and Silvestre, A. J. D. (1999). “Total fractionation and analysis of organic components of industrial Eucalyptus globulus kraft black liquor," APPITA J. 52(3), 213-217, 225.

New Logic (1999). "Black liquor treatment for pulp mills," Application note, New Logic International, Inc.

Niemelä, K., and Alén, R. (1999). "Characterization of pulping liquors," in: Analytical Methods in Wood Chemistry, Pulping, and Papermaking, E. Sjöström, and R. Alén (eds.), Springer, Heidelberg, pp. 193-231. DOI: 10.1007/978-3-662-03898-7_7

Niemelä, K., Alén, R., and Sjöström, E. (1985). "The formation of carboxylic acids during kraft and kraft-anthraquinone pulping of birch wood," Holzforschung 39, 167172. DOI: $10.1515 / \mathrm{hfsg} .1985 .39 .3 .167$

Niemi, H., Lahti, J., Hatakka, H., Karki, S., Rovio, S., Kallioinen, M., Manttari, M., and Louhi-Kultanen, M. (2011). "Fractionation of organic and inorganic compounds from black liquor by combining membrane separation and crystallization," Chem. Eng. Technol. 34(4), 593-598. DOI: 10.1002/ceat.201000520

Nikkanen, S. (1993). "Liquor heat treatment and high-dry-solids firing," Bioresour. Technol. 46(1-2), 173-176. DOI: 10.1016/0960-8524(93)90070-R

Nikitin, V. M., Obolenskaya, A. V., Skachkov, V. M., and Ivanenko, A. D. (1963). "Precipitation of alkali lignin with carbon dioxide under pressure," Bum. Prom. 38(11), 14-15.

Norgren, M., and Edlund, H. (2001). "Stabilization of kraft lignin solutions by surfactant additions," Colloids Surf. A Physicochem. Eng. Aspects 194, 239-248. DOI: 10.1016/S0927-7757(01)00806-8

Norgren, M., and Edlund, H. (2003). "Ion specific differences in salt induced precipitation of kraft lignin," Nordic Pulp Paper Res. J. 18(4), 400-403. DOI: 10.3183/NPPRJ-2003-18-04-p400-403 
Norgren, M., and Edlund, H. (2014). "Lignin: Recent advances and emerging applications," Current Opinion Colloid Interface Sci. 19(5), 409-416. DOI: 10.1016/j.cocis.2014.08.004

Norgren, M., Edlund, H., and Wågberg, L. (2002a). "Aggregation of lignin derivatives under alkaline conditions. Kinetics and aggregate structure," Langmuir 18(7), 28592865. DOI: $10.1021 / \mathrm{la0} 11627 \mathrm{~d}$

Norgren, M., Edlund, H., Wagberg, L., and Annergren, G. (2002b). "Fundamental physical aspects on lignin dissolution,” Nordic Pulp Paper Res. J. 17(4), 370-373. DOI: 10.3183/NPPRJ-2002-17-04-p370-373

Norgren, M., Edlund, H., Wågberg, L., Lindström, B., and Annergren, G. (2001). "Aggregation of kraft lignin derivatives under conditions relevant to the process. Part 1. Phase behavior," Colloids Surf. A Physicochem Eng. Aspects 194(1), 85-96. DOI: 10.1016/S0927-7757(01)00753-1

Norgren, M., and Mackin, S. (2009). "Sulfate and surfactants as boosters of kraft lignin precipitation," Ind. Eng. Chem. Res. 48(10), 5098-5104. DOI: 10.1021/ie900141s

Nyman, V., Rose, G., and Ralston, J. (1986). "The colloidal behavior of kraft lignin and lignosulfonates," Colloids Surf. 21, 125-147. DOI: 10.1016/0166-6622(86)80087-7

Ohman, F., and Theliander, H. (2001). "Filtration properties of lignin precipitated from black liquor," 2001 International Chemical Recovery Conference: Changing Recovery Technology to Meet the Challenges of the Pulp and Paper Industry, Whistler, Canada, pp. 19-25.

Ohman, F., and Theliander, H. (2007). "Filtration properties of lignin precipitated from black liquor," TAPPI J. 6(7), 3-9.

Ohman, F., Wallmo, H., and Theliander, H. (2007a). "A novel method for washing lignin precipitated from kraft black liquor - Laboratory trials," Nordic Pulp Paper Res. J. 22(1), 9-16. DOI: 10.3183/NPPRJ-2007-22-01-p009-016

Ohman, F., Wallmo, H., and Theliander, H. (2007b). "Precipitation and filtration of lignin from black liquor of different origin," Nordic Pulp Paper Res. J. 22(2), 188193. DOI: 10.3183/NPPRJ-2007-22-02-p188-193

Ooi, Z. Y., Othman, N., and Noah, N. F. M. (2016). "Response surface optimization of kraft lignin recovery from pulping wastewater through emulsion liquid membrane process," Desal. Water Treat. 57(17), 7823-7832. DOI:

10.1080/19443994.2015.1024754

Österberg, M., Sipponen, M. H., and Henriksson, G. (2017). "Editorial: From understanding the biological function of lignin in plants to production of colloidal lignin particles," Nordic Pulp Paper Res. J. 32(4), 483-484. DOI: 10.3183/NPPRJ2017-32-04-p483-484

Oye, R., Langfors, N. G., Phillips, F. H., and Higgins, H. G. (1977). "The properties of kraft black liquors from various eucalypts and mixed tropical hardwoods," Appita 31(1), 33-40.

Ozdenkci, K., De Blasio, C., Muddassar, H. R., Melin, K., Oinas, P., Koskinen, J., Sarwar, G., and Järvinen, M. (2017). "A novel biorefinery integration concept for lignocellulosic biomass," Energy Conver. Manag. 149, 974-987. DOI: 10.1016/j.enconman.2017.04.034

Pakkanen, H., and Alén, R. (2012). "Molecular mass distribution of lignin from the alkaline pulping of hardwood, softwood, and wheat straw," J. Wood Chem. Technol. 32, 279-293. DOI: 10.1080/02773813.2012.659321 
Peter-Varbanets, M., Zurbrügg, C., Swartz, C., and Pronk, W. (2009). "Decentralized systems for potable water and the potential of membrane technology," Water Res. 43, 245-265. DOI: 10.1016/j.watres.2008.10.030

Pirttinen, E., Stenius, P., and Kovasin, K. (2007). "Surfactant phase equilibria and separation of amphiphilic extractives from black liquor in kraft cooking of wood," $J$. Dispersion Sci. Technol. 28(1), 5-10. DOI: 10.1080/01932690600992852

Pollak, A., Keilen Jr., J. J., and Drum, L. F. (1944). "Method of producing lignin from black liquor," U.S. Patent No. 2,464,828.

Pye, E. K. (2006). "Industrial lignin production and applications," Biorefineries Industrial Processes and Products, Wiley-VCH Verlag GmbH, Vol. 2, pp. 165-200.

Ragnar, M., Lindgren, C. T., and Nilvebrant, N.-O. (2000). "pK(a)-values of guaiacyl and syringyl phenols related to lignin," J. Wood Chem. Technol. 20(3), 277-305. DOI: 10.1080/02773810009349637

Rastegarfar, N., Behrooz, R., and Bahramifar, N. (2015). "Electrocoagulation treatment of black liquor from soda-AQ pulping of wheat straw," Environ. Monit. Assess. 187, article no. 45. DOI: 10.1007/s10661-014-4245-0

Rinaldi, R., Jastrzebski, R., Clough, M. T., Ralph, J., Kennema, M., Bruijnincx, P. C. A., and Weckhuysen, B. M. (2016). "Paving the way for lignin valorisation: Recent advances in bioengineering, biorefining and catalysis," Angew. Chem. Int. Ed. 55(29), 8164-8215. DOI: 10.1002/anie.201510351

Roberts, J. E., Spontak, R. J., Jameel, H., and Khan, S. A. (1996). “A novel approach to black liquor viscosity reduction using salt additives," TAPPI J. 79(8), 167-174.

Rudatin, S., Sen, Y. L., and Woerner, D. L. (1989). "Association of kraft lignin in aqueous solution," in: W. G. Glasser, and S. Sarkanen, S. (eds.), Lignin. Properties and Materials, ACS Symp. Ser. 397, Ch. 11, pp. 144-154. DOI: 10.1021/bk-19890397.ch011

Rydholm, S. A. (1965). Pulping Processes, Interscience Publ., New York, NY, 1269 pp.

Sameni, J., Krigstin, S., and Sain, M. (2016). "Characterization of lignins isolated from industrial residues and their beneficial uses," BioResources 11(4), 8435-8456. DOI: 10.15376/biores.11.4.8435-8456

Sarkanen, K. V., and Ludwig, C. H. (eds.) (1971). Lignins. Occurrence, Formation, Structure and Reactions, Wiley-Interscience, New York, NY.

Saththasivam, J., Loganathan, K., and Sarp, S. (2016). "An overview of oil-water separation using gas flotation systems," Chemosphere 144, 671-680. DOI: 10.1016/j.chemosphere.2015.08.087

Schulze, H. (1882). "Schwefelarsen in wässriger Lösung," J. Prakt. Chem. 25, 431-452. DOI: $10.1002 /$ prac. 18820250142

Servaes, K., Varhimo, A., Dubreuil, M., Bulut, M., Vandezande, P., Siika-aho, M., Sirvio, J., Kruus, K., Porto-Carrero, W., and Bongers, B. (2017). "Purification and concentration of lignin from the spent liquor of the alkaline oxidation of woody biomass through membrane separation technology," Indust. Crops Prod. 106, 86-96. DOI: 10.1016/j.indcrop.2016.10.005

Sevastyanova, O., Helander, M., Chowdhury, S., Lange, H., Wedin, H., Zhang, L., Ek, M., Kadla, J. F., Crestini, C., and Lindström, M. E. (2014). "Tailoring the molecular and thermos-mechanical properties of kraft lignin by ultrafiltration," J. Appl. Polym. Sci. 131(18), 40799/1-40799/11. DOI: 10.1002/app.40799 
Shi, X. F., Tal, G., Hankins, N. P., and Gitis, V. (2014). "Fouling and cleaning of ultrafiltration membranes: A review," J. Water Proc. Eng. 1, 121-138. DOI: 10.1016/j.jwpe.2014.04.003

Sixta, H. (ed.) (2006). Handbook of Pulp, Weley-VCH, Weinheim, 1352 pp.

Sjöström, E. (1983). "Alternatives for balanced production of fibers, chemicals, and energy from wood," J. Appl. Polym. Sci. 37, 577-592.

Sjöström, E. (1989). "The origin of charge on cellulosic fibers," Nordic Pulp Paper Res. J. 4(2), 90-93. DOI: 10.3183/NPPRJ-1989-04-02-p090-093

Sjöström, E. (1993). Wood Chemistry: Fundamentals and Applications, Academic Press, San Diego, CA, $2^{\text {nd }}$ Ed., 293 pp.

Söderhjelm, L. (1988). "Factors affecting the viscosity of strong black liquor," Appita J. 41(5), 389-392.

Söderhjelm, L., and Sågfors, P.-E. (1994). "Fractors influencing the viscosity of kraft black liquors," J. Pulp Paper Sci. 20(4), J106-J110.

Söderhjelm, L., Sågfors, P.-E., and Janson, J. (1992). "Black liquor viscosity," Paperi Рии 74(1), 56-58.

Souto, F., Calado, V., and Pereira, N. 2015). "Carbon fiber from lignin: A literature review," Materia-Rio de Janeiro 20(1), 100-114. DOI: 10.1590/S1517707620150001.0012

Stoklosa, R. J., Velez, J., Kelkar, S., Saffron, C. M., Thies, M. C., and Hodge, D. B. (2013). "Correlating lignin structural features to phase partitioning behavior in a novel aqueous fractionation of softwood kraft black liquor," Green Chem. 15(10), 2904-2912. DOI: 10.1039/c3gc41182f

Suhas, Gupta, V. K., Carrott, P. J. M., Singh, R., Chaudhary, M., and Kushwaha, S. (2016). "Cellulose: A review as natural, modified and activated carbon adsorbent," Bioresour. Technol. 216, 1066-1076. DOI: 10.1016/j.biortech.2016.05.106

Sun, R. C., Tomkinson, J., and Bolton, J. (1999). "Effects of precipitation $\mathrm{pH}$ on the physico-chemical properties of the lignins isolated from the black liquor of oil palm empty fruit bunch fibre pulping," Polym. Degrad. Stability 63(2), 195-200. DOI: 10.1016/S0141-3910(98)00091-3

Sunpine (2015). "SunPine, from crude tall oil to green diesel, printing ink and perfume," http://www.paperadvance.com/blogs/2015-09-21-18-40-27/5998-sunpine-fromcrude-tall-oil-to-green-diesel-printing-ink-and-perfume.html

Surina, I., Jablonsky, M., Haz, A., Sladkova, A., Briskarova, A., Kacik, F., and Sima, J. (2015). "Characterization of non-wood lignin precipitated with sulphuric acid of various concentrations," BioResources 10(1), 1408-1423. DOI: 10.15376/biores.10.1.1408-1423

Tadros, T. F. (1991). "Steric stabilization and flocculation by polymers," Polymer J. 23(5), 683-696. DOI: 10.1295/polymj.23.683

Tarasov, D., Leitch, M., Fatehi, P. (2018). "Lignin-carbohydrate complexes: Properties, applications, analyses, and methods of extraction: A review," Biotech. Biofuels 11, article no. 269. DOI: 10.1186/s13068-018-1262-1

Teguia, C. D., Albers, R., and Stuart, P. R. (2017). “Analysis of economically viable lignin-based biorefinery strategies implemented within a kraft pulp mill," TAPPI J. 16(3), 157-169.

Toledano, A., Garcia, A., Mondragon, I., and Labidi, J. (2010a). "Lignin separation and fractionation by ultrafiltration," Separ. Purif. Technol. 71(1), 38-43. DOI: 10.1016/j.seppur.2009.10.024 
Toledano, A., Serrano, L., Garcia, A., Mondragon, I., and Labidi, J. (2010b). "Comparative study of lignin fractionation by ultrafiltration and selective precipitation," Chem. Eng. J. 157(1), 93-99. DOI: 10.1016/j.cej.2009.10.056

Tomani, P. (2010). “The LignoBoost process," Cellulose Chem. Technol. 44, 53-58.

Tomani, P., Axegard, P., Berglin, N., Lovell, A., and Nordgren, D. (2011). "Integration of lignin removal into a kraft pulp mill and use of lignin as a biofuel," Cellulose Chem. Technol. 45(7-8), 533-540.

Tomani, P., Axegard, P., Norgerg, L, and Åkerlund, L.-E. (2012). "Lignin removal from different black liquors," 2012 TAPPI PEERS Conf.: Building a Sustainable Future, TAPPI Press, Atlanta, pp. 835-843.

Tomlinson Sr., G., and Tomlinson Jr., G. (1946). "Method of treating cellulosic material," U.S. Patent No. 2,406,867.

Uloth, V., and Wearing, J. T. (1989a). "Kraft lignin recovery. Acid precipitation versus ultrafiltration, Part 1: Laboratory test results," Pulp Paper Can. 90, 67-71; T357T360.

Uloth, V., and Wearing, J. T. (1989b). "Kraft lignin recovery. Acid precipitation versus ultrafiltration, Part 2: Technology and economics," Pulp Paper Can. 90, 34-37; T310T314.

Vakkilainen, E. K. (2007). Kraft Recovery Boilers - Principles and Practice, $2^{\text {nd }}$ printing, Helsinki University of Technology, Energy Engineering and Environmental Protection, Espoo, 246 pp.

Vakkilainen, E., and Välimäki, E. (2009). "Effect of lignin separation to black liquor and recovery boiler operation," in: TAPPI Conference, Memphis, TN, United States, Vol 3, 1515-1556.

Välimäki, E., Niemi, P., and Haaga, K. (2010). "A case study on the effects of lignin recovery on recovery boiler operation," in: TAPPI/PAPTAC International Chemical Recovery Conference, Williamsburg, VA, United States. Vol.2, 148-156.

Velez, J., and Thies, M. C. (2013). "Solvated liquid-lignin fractions from a kraft black liquor," Bioresour. Technol. 148, 586-590. DOI: 10.1016/j.biortech.2013.08.097

Velez, J., and Thies, M. C. (2016). "Liquid lignin from the SLRP process: The effect of processing conditions and black-liquor properties," J. Wood Chem. Technol. 36(1), 27-41. DOI: 10.1080/02773813.2015.1039545

Verwey, E. J. W., and Overbeek, J. Th. G. (1948). Theory of the Stability of Lyophobic Colloids, Elsevier, New York, NY.

Vishtal, A., and Kraslawski, A. (2011). "Challenges in industrial applications of technical lignins," BioResources 6(3), 3547-3568. DOI: 10.15376/biores.6.3.3547-3568

Wallberg, O., and Jönsson, A. S. (2006). "Separation of lignin in kraft cooking liquor from a continuous digester by ultrafiltration at temperatures above 100 degrees C," Desalination 195, 187-200. DOI: 10.1016/j.desal.2005.11.011

Wallberg, O., Jönsson, A. S., and Wimmerstedt, R. (2003a). "Fractionation and concentration of kraft black liquor lignin with ultrafiltration," Desalination 154, 187 199. DOI: 10.1016/S0011-9164(03)80019-X

Wallberg, O., Jönsson, A. S., and Wimmerstedt, R. (2003b). "Ultrafiltration of kraft black liquor with a ceramic membrane," Desalination 156, 145-153, article no. PII S00119164(03)00337-0, DOI: 10.1016/S0011-9164(03)00337-0

Wallmo, H. (2008). Lignin Extraction from Black Liquor - Precipitation, Filtration, and Washing, Ph.D. thesis, Univ. Götteborg, Sweden. 
Wallmo, H., Richards, T., and Theliander, H. (2007). "Lignin precipitation from kraft black liquors: Kinetics and carbon dioxide absorption," Paperi Puu 89(7), 436-442.

Wallmo, H., Richards, T., and Theliander, H. (2009a). "An investigation of process parameters during lignin precipitation from kraft black liquors: A step towards an optimised precipitation operation," Nordic Pulp Paper Res. J. 24(2), 158-164. DOI: 10.3183/NPPRJ-2009-24-02-p158-164

Wallmo, H., Theliander, H., Jönsson, A. S., Wallberg, O., and Lindgren, K. (2009b). "The influence of hemicelluloses during the precipitation of lignin in kraft black liquor," Nordic Pulp Paper Res. J. 24(2), 165-171. DOI: 10.3183/NPPRJ-2009-2402-p165-171

Wang, K., Xu, F., and Sun, R. C. (2010). "Molecular characteristics of kraft-AQ pulping lignin fractionated by sequential organic solvent extraction," Int. J. Molec. Sci. 11(8), 2988-3001. DOI: 10.3390/ijms11082988

Wang, Z. J., Wang, X. J., Fu, Y. J., Li, Z. Q., Zhang, F. S., and Qin, M. H. (2015). "Colloidal behaviors of lignin contaminants: Destabilization and elimination for oligosaccharides separation from wood hydrolysate," Separ. Purif. Technol. 145, 1-7. DOI: 10.1016/j.seppur.2015.03.001

Wartena, R., Winnick, J., and Pfromm, P. H. (2002). "Recycling wood pulping chemicals by molten salt electrolysis: Cyclic voltammetry of mixtures containing $\mathrm{Na}_{2} \mathrm{CO}_{3}$ and $\mathrm{Na}_{2} \mathrm{SO}_{4}$," J. Appl. Electrochem. 32(4), 415-424. DOI: 10.1023/A:1016334307899

Weerachanchai, P., Kwak, S. K., and Lee, J. M. (2014). "Effects of solubility properties of solvents and biomass on biomass pretreatment," Bioresour. Technol. 170, 160-166. DOI: 10.1016/j.biortech.2014.07.057

Weinhaus, O., Bernaczyk, Z., and Pecina, H. (1990). "Research into the precipitation of lignin from sulfate black liquors, particularly by carbon-dioxide," Papier 44(11), 563569.

Whalen, D. M., and Tokoli, E. G. (1968). "Lignin precipitation from black liquor in the presence of chloro, bromo or nitro containing hydrocarbons," U.S. Patent No. 3,546,200.

Wising, L., Algehed, J., Berntsson, T., and Delin, L. (2006). "Consequences of lignin precipitation in the pulp and paper industry," TAPPI J. 5(1), 3-8.

Yahya, M. A., Al-Qodah, Z., and Ngah, C. W. Z. (2015). "Agricultural bio-waste materials as potential sustainable precursors used for activated carbon production: A review," Renew. Sustain. Energy Rev. 46, 218-235. DOI: 10.1016/j.rser.2015.02.051

Yang, W. B., Mu, H. Z., and Huang, Y. C. (2003). "Treatment of black liquor from the papermaking industry by acidification and reuse,” J. Environ. Sci. 15(5), 697-700.

Ye, Y. Y., Liu, Y. Q., and Chang, J. (2014). "Application of solubility parameter theory to organosolv extraction of lignin from enzymatically hydrolyzed cornstalks," BioResources 9(2), 3417-3427. DOI: 10.15376/biores.9.2.3417-3427

Yuan, T. Q., He, J., Xu, F., and Sun, R. C. (2009). "Fractionation and physico-chemical analysis of degraded lignins from the black liquor of Eucalyptus pellita KP-AQ pulping," Polymer Degrad. Stabil. 94(7), 1142-1150. DOI:

10.1016/j.polymdegradstab.2009.03.019

Yusof, N., and Ismail, A. F. (2012). "Post spinning and pyrolysis processes of polyacrylonitrile (PAN)-based carbon fiber and activated carbon fiber: A review," J. Anal. Appl. Pyrolysis 93, 1-13. DOI: 10.1016/j.jaap.2011.10.001 
Zaman, A. A., and Fricke, A. L. (1994). "Newtonian viscosity of high solids kraft black liquors: Effects of temperature and solids concentrations," Ind. Eng. Chem. Res. 33, 428-435. DOI: 10.1021/ie00026a039

Zaman, A. A., and Fricke, A. L. (1995). "Effects of pulping conditions and black liquor on viscosity of softwood kraft black liquors: predictive models," TAPPI J. 78(10), 107-119.

Zaman, A. A., and Fricke, A. L. (1996). "Effect of pulping conditions and black liquor composition on Newtonian viscosity of high solids kraft black liquors," Ind. Eng. Chem. Res. 35, 590-597. DOI: 10.1021/ie950202h

Zeman, L. J., and Zydney, A. L. (2017). Microfiltration and Ultrafiltration: Principles and Applications, Taylor and Francis, Abingdon, UK. DOI: 10.1201/9780203747223

Zhao, W. W., Simmons, B., Singh, S., Ragauskas, A., and Cheng, G. (2016). "From lignin association to nano-/micro-particle preparation: Extracting higher value of lignin," Green Chem. 18(21), 5693-5700. DOI: 10.1039/c6gc01813k

Zhu, W. Z., and Theliander, H. (2011). "Equilibrium of lignin precipitation," in: $16^{\text {th }}$ International Symposium on Wood, Fiber and Pulping Chemistry, Proceedings, L. Wang, S. Kuang, Q. Hou, C. Cao, C. L. Si, and H. J. Zang (eds.), pp. 195-199.

Zhu, W. Z., and Theliander, H. (2015). "Precipitation of lignin from softwood black liquor: An investigation of the equilibrium and molecular properties of lignin," BioResources 10(1), 1696-1714. DOI: 10.15376/biores.10.1.1696-1715

Zhu, W. Z., Westman, G., and Theliander, H. (2014). "Investigation and characterization of lignin precipitation in the LignoBoost process," J. Wood Chem. Technol. 34(2), 7797. DOI: $10.1080 / 02773813.2013 .838267$

Zhu, W. Z., Westman, G., and Theliander, H. (2016). "Lignin separation from kraft black liquor by combined ultrafiltration and precipitation: A study of solubility of lignin with different molecular properties," Nordic Pulp Paper Res. J. 31(2), 270-278. DOI: 10.3183/NPPRJ-2016-31-02-p270-278

Ziesig, R., Tomani, P., Schweinebarth, H., Norberg, L., and Theliander, H. (2014a). "Production of a pure lignin product, Part 1: Distribution and removal of inorganics in Eucalyptus globulus kraft lignin," TAPPI J. 13(3), 65-72.

Ziesig, R., Tomani, P., and Theliander, H. (2014b). "Production of a pure lignin product. Part 2: Separation of lignin from membrane filtration permeates of black liquor," Cellulose Chem. Technol. 48(9-10), 805-811.

Zinkel, D. F., and Russell, J. (eds.) (1989). Naval Stores: Production, Chemistry, Utilization, Pulp Chemicals Assoc., New York, NY. DOI: 10.1007/978-3-642-740756_26 


\section{ERRATUM}

Corrections were made in June 2019 in response to comments from a vigilant reader, who noticed two mistakes, some missing citations, and some unclear points. Italic text indicates the text that is changed or new. Some new citations corresponding to the changed items were added to the References Cited list.

Page 2322, third full paragraph:

Original: Haddad et al. (2016) achieved poor filterability when using a certain electrochemical approach to acidify black liquor; the slow filtering was attributed to an inability to achieve a sufficiently low $\mathrm{pH}$.

New: Haddad et al. (2016) observed fouling of a membrane when using a certain electrochemical approach that resulted in decreased $\mathrm{pH}$ (from about 12.5 to as low as 10.5) of black liquor.

Page 2326:

Original: Electrolysis

Electrolysis can be used to treat black liquor even in the absence of a membrane (Ghatak 2009a,b; Ghatak et al. 2010). In the cited work, wheat straw and sugarcane bagasse lignin accumulated at the anode and hydrogen was evolved at the cathode.

New: Electrolysis and Electrodialysis

Electrolysis can be used to treat black liquor even in the absence of a membrane (Cloutier et al. 1993, 1994, 1995; Blanco et al. 1996; Negro et al. 2005; Ghatak 2009a,b; Ghatak et al. 2010). Cloutier et al. (2005) reported that deposition of lignin onto the anode could be avoided by keeping the $\mathrm{pH}$ high. This approach has potential to regenerate $\mathrm{NaOH}$ at the same time separating some of the lignin. Negro et al. (2005) were able to minimize fouling of the anode with lignin deposition by use of a Pt electrode and a high current density. In the work by Ghatak and coworkers, wheat straw and sugarcane bagasse lignin accumulated at the anode and hydrogen was evolved at the cathode.

Page 2327:

Original: Haddad et al. (2017a,b) reported lignin separation from softwood kraft black liquor with an electro-membrane process. The electrolysis reaction resulted in a drop of $\mathrm{pH}$, bringing about the precipitation of lignin. The electrochemical procedure achieved the separation with less chemical addition, and $\mathrm{NaOH}$ could be recovered. However, substantial fouling of the membrane caused abandonment of the experiment. An earlier attempt (Haddad et al. 2016) showed that the electrolysis reaction was unable to depress the $\mathrm{pH}$ enough to achieve effective precipitation. Similar

New: Haddad et al. (2017a-c) reported lignin separation from softwood kraft black liquor using an electro-dialysis process. The process resulted in a drop of $\mathrm{pH}$, bringing about the precipitation of lignin. The electrochemical procedure achieved the separation with less chemical addition, and $\mathrm{NaOH}$ could be recovered. By using pulses of applied voltage it was possible to reduce fouling while recovering a relatively high lignin yield (Haddad et al. 2017b). Similar 